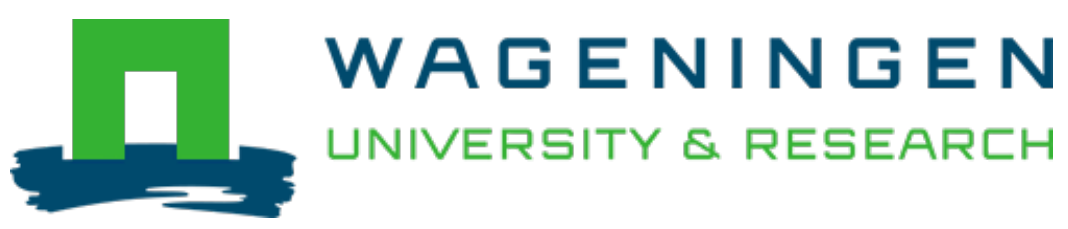

\title{
Twenty-five years of total antioxidant capacity measurement of foods and biological fluids: merits and limitations
}

\author{
Journal of the Science of Food and Agriculture \\ Pellegrini, Nicoletta; Vitaglione, Paola; Granato, Daniel; Fogliano, Vincenzo \\ https://doi.org/10.1002/jsfa. 9550
}

This article is made publicly available in the institutional repository of Wageningen University and Research, under the terms of article $25 \mathrm{fa}$ of the Dutch Copyright Act, also known as the Amendment Taverne. This has been done with explicit consent by the author.

Article 25 fa states that the author of a short scientific work funded either wholly or partially by Dutch public funds is entitled to make that work publicly available for no consideration following a reasonable period of time after the work was first published, provided that clear reference is made to the source of the first publication of the work.

This publication is distributed under The Association of Universities in the Netherlands (VSNU) 'Article $25 \mathrm{fa}$ implementation' project. In this project research outputs of researchers employed by Dutch Universities that comply with the legal requirements of Article $25 \mathrm{fa}$ of the Dutch Copyright Act are distributed online and free of cost or other barriers in institutional repositories. Research outputs are distributed six months after their first online publication in the original published version and with proper attribution to the source of the original publication.

You are permitted to download and use the publication for personal purposes. All rights remain with the author(s) and / or copyright owner(s) of this work. Any use of the publication or parts of it other than authorised under article $25 \mathrm{fa}$ of the Dutch Copyright act is prohibited. Wageningen University \& Research and the author(s) of this publication shall not be held responsible or liable for any damages resulting from your (re)use of this publication.

For questions regarding the public availability of this article please contact openscience.library@wur.nl 


\title{
Twenty-five years of total antioxidant capacity measurement of foods and biological fluids: merits and limitations
}

\author{
Nicoletta Pellegrini, ${ }^{a, b *} \odot$ Paola Vitaglione, ${ }^{c}$ Daniel Granato ${ }^{d}$ \\ and Vincenzo Fogliano ${ }^{b}$
}

\begin{abstract}
This review summarises $\mathbf{2 5}$ years of investigations on antioxidants research in foods and biological fluids and critically analyses the merits and limitations of using the total antioxidant capacity (TAC) measurement in the metabolomic era. An enormous bulk of knowledge was produced regarding the antioxidant capacity of foods and large TAC databases were developed. A direct link between a food TAC value and any health benefit is erroneous and has led to several cases of consumer deception. However, the striking epidemiological evidence associating a high dietary TAC with some disease prevention and the availability of well-constructed TAC databases deserve attention and must be taken into account to establish the usefulness of measuring TAC in both foods and biological samples. The in vivo TAC measurement, usually performed in plasma, is influenced by many external factors, such as dietary habits, as well as environmental and behavioural factors, which are integrated towards homeostatic control by fine physiological mechanisms with high inter-individual variability. Therefore, plasma TAC cannot be considered as a unique biomarker of individual antioxidant status. However, the combined evaluation of plasma TAC with known markers of disease, individual metabolism, inflammation and genetics, as well as with markers of gut microbiota composition and activity, may lead to the identification of populations that are more responsive to food/diet TAC. In this framework, the appropriate use of TAC measurement both in food and in vivo can still provide support for the interpretation of complex phenomena and be a tool for sample screening when making a quick decision toward in-depth research investigations.
\end{abstract}

(c) 2018 Society of Chemical Industry

Keywords: in vitro total antioxidant capacity; food, diet; plasma total antioxidant capacity; food antioxidants; phenolic compounds; epidemiological studies

\section{INTRODUCTION OF THE TAC CONCEPT}

In the 1990s, many epidemiological studies demonstrated that an increased consumption of fruit and vegetables was associated with protection against various diseases, including cancers ${ }^{1-3}$ and cardio- and cerebrovascular diseases. ${ }^{4,5}$ The hypothesis that the major protective role of such foods could have been a result of the antioxidants contained within them rapidly became popular and opened the way for the 'antioxidant hypothesis'. Fruit and vegetables contain not only vitamins $\mathrm{C}, \mathrm{E}$ and $\beta$-carotene, but also a plethora of bioactive molecules, which mainly belong to the chemical class of phenolic compounds. Such molecules are characterised by chemical diversity, which complicates the measurement of the levels of single antioxidants. Therefore, the concept of total antioxidant capacity (TAC), including the synergic and redox interactions between the different molecules present in the food, was introduced. This concept has been applied to foods and biological fluids for several decades, aiming to explore the hypothesis that the protective role of plant foods could be linked to their antioxidant content. Additionally, epidemiological studies have also explored whether a high intake of antioxidants is associated with a low risk of several non-communicable diseases and health outcomes.

To measure the TAC, a variety of assays was developed, although the use of TAC index as a surrogate marker for food quality and diet is now deeply criticised. . $^{6,7}$ This review summarises more than 25 years of investigations on antioxidant research in foods and biological fluids and critically analyses the merits and limitations of using TAC measurement in the metabolomic era.

\section{FROM LIPID OXIDATION TO ANTIOXIDANT ANALYSIS OF FOODS}

It is well known that the main oxidants both in food and in humans are reactive oxygen species (ROS) and reactive nitrogen

\footnotetext{
Correspondence to: N Pellegrini, Department of Food and Drug, Human Nutrition Unit, University of Parma, Parco Area delle Scienze, 47/A 43124 - Parma, Italy. E-mail: nicoletta.pellegrini@unipr.it

a Department of Food and Drug, University of Parma, Parma, Italy

b Food Quality and Design Group, Wageningen University and Research, Wageningen, The Netherlands

c Department of Agricultural Sciences, University of Naples 'Federico II', Portici, Italy

d Department of Food Engineering, State University of Ponta Grossa, Ponta Grossa, Brazil
} 
species (RNS). ${ }^{8}$ Oxidised foods lose quality and are rejected by consumers. The overproduction of oxidised substances via redox reactions (e.g. lipid oxidation) results in oxidative stress or nitrosative stress in biological systems, leading to an overproduction of pro-inflammatory cytokines and an increased risk of several illnesses in humans. ${ }^{9-11}$

Lipid oxidation is one of the main non-microbial factors responsible for quality deterioration in various foods. ${ }^{12}$ Overall, the chemical stability of lipids depends on the balance between pro-oxidant and antioxidant components in the food matrix and, in turn, this depends on the $\mathrm{pH}$, chemical structures of antioxidants, as well as the presence of transition metals in the medium. All of these factors influence the various steps of the radical reaction leading to the formation of lipid peroxides and the volatile off-flavours responsible for rancid notes. ${ }^{13}$ Consequently, the first measurements of in vitro antioxidant capacity of foods and beverages aimed to establish a relationship with lipid oxidation phenomena.

\section{Lipid analysis: the Rancimat and thiobarbituric acid reactive substances (TBARS) tests}

Many tests can be used to assess the oxidation extent of lipid-rich foods, such as the levels of free fatty acids formed upon the hydrolytic degradation of lipid molecules, peroxide value, $p$-anisidine value (i.e. the content of secondary products of lipid oxidation) and the analysis of conjugated dienes and trienes. ${ }^{14}$ In addition to these tests, the resistance of oils and fats to oxidation can also be evaluated by accelerated stability tests, such as the Rancimat test. This test has also been used to assess whether the antioxidant activity of a compound or a mixture of compounds resists at high temperatures $\left(\geq 100^{\circ} \mathrm{C}\right.$ or higher $)$ and in the presence of exogenous oxidation promoters (i.e. $\mathrm{Fe}^{2+}$ ). It comprises an oxidative stability index, which is characterized by the induction time (h) at a certain temperature. The test is represented by a kinetic reaction in which the antioxidant concentration (i.e. $\mathrm{mg}$ $\mathrm{kg}^{-1}$ ) added into the food system is plotted against the induction time (h). The Rancimat test has also been used to assess indirectly the antioxidant capacity of foods. ${ }^{15,16}$ Currently, this test has been used to compare the antioxidant activity of several water-soluble and liposoluble antioxidants, such as tocopherols, ascorbyl palmitate, ascorbic acid, citric acid, phenolic-rich extracts, isolated phenolic compounds and their derivatives, added into vegetal oils and other foods. ${ }^{17-20}$ Although the Rancimat test is widely used to evaluate the TAC of foods, it should not be used to assess the antioxidant status of individuals or to evaluate human fluids (i.e. blood and urine).

To overcome the limitations of Rancimat, the measurement of TBARS was introduced to analyse both food products and biological fluids. TBARS are secondary lipid oxidation products and the measurement of their concentration in foods, blood and tissue homogenates is widely used as a technique for the evaluation of lipid oxidation both in vitro and in vivo. ${ }^{21-24}$ One of the main products formed from the degradation of hydroperoxides in the oxidative process is malondialdehyde (MDA), a three-carbon dialdehyde $\left(\mathrm{C}_{3} \mathrm{H}_{4} \mathrm{O}_{2}\right)$ that is produced when polyunsaturated fatty acids have at least three double bonds. In this regard, the TBARS test was initially proposed to mainly measure MDA levels in a matrix. However, other products resulting from lipid oxidation, such as allenal and alkadienal, also react with TBA; therefore, the reaction products are referred to as thiobarbituric acid reactive substances. ${ }^{25}$

Although the TBARS test is generally well accepted and easy to perform, it presents variable reproducibility and involves long reaction times. To overcome these limitations, MDA levels in foods and biological fluids may be analysed by chromatographic methods, especially high-performance liquid chromatography. ${ }^{26,27}$

\section{Development of rapid in vitro methods for TAC assessment}

Lipid oxidation represents only a small part of the complex equilibrium of oxidants-antioxidants that is present in foods and in the human body. The idea of measuring the TAC of foods and biological fluids by obtaining a value that could integrate the individual antioxidant actions of different compounds and their additive, synergistic or antagonistic interactions was immediately accepted by scientists, aiming to reveal the functional effects of foods, supplements and diets. ${ }^{7,28,29}$ The most common assays comprise measurement of oxygen radical antioxidant capacity using different fluorescent probes (ORAC), ${ }^{30}$ measurement of total radical-trapping antioxidant parameter (TRAP), inhibition of lipid peroxidation, ${ }^{31}$ the crocin bleaching antioxidant assay, ${ }^{32}$ measurement of 2,2-azino-bis(3-ethylbenzothiazoline-6-sulphonic acid (ABTS) (also called the Trolox equivalent antioxidant capacity; TEAC), ${ }^{33}$ measurement of 2,2-diphenyl-1-picrylhydrazyl $(\mathrm{DPPH}){ }^{34}$ measurement of ferric reducing antioxidant potential (FRAP), ${ }^{35}$ measurement of Folin-Ciocalteu's phenol reagent reducing capacity, ${ }^{36,37}$ and the cupric reducing antioxidant capacity (CUPRAC) assay. ${ }^{38}$ The possibility of using many of those assays directly on the solid food, without any extraction step, enlarged the potentiality of TAC assays by also taking into account the relevance of the food insoluble fraction. ${ }^{39}$

Several reviews provide a description in terms of the chemical kinetics and thermodynamics, reaction mechanisms, and analytical performance characteristics of these analytical methods. ${ }^{30,40}$

The intriguing idea of directly connecting the food TAC with the beneficial effects related to the intake of antioxidant molecules boosted the application of these in vitro methods, which were largely adopted to claim the beneficial effects of all kind of foods. A large number of research studies describe the use of different TAC methods to evaluate the effects of foods on oxidative stress in humans both in short- and long-term studies (for a meta-analysis, see Lettieri-Barbato et al. ${ }^{41}$ ). Each method employs different analytical conditions, making the results incomparable with each other and poorly representative of the physiological action of the single molecules. Also noteworthy is the fact that these assays do not account for synergistic and antagonist interactions between antioxidants in biological samples. ${ }^{32,42}$ Therefore, the in vitro antioxidant capacity does not reflect the real beneficial health effects in vivo and the usefulness and applicability of in vitro assays have been questioned. ${ }^{43}$

More recently, multiple assays aiming to measure the non-enzymatic antioxidant capacity (NEAC) of biological fluids ${ }^{44}$ or human cells ${ }^{45}$ have been developed. ${ }^{46}$ Some of these methods include chemical and cellular-based methods. ${ }^{47-51}$ However, the results from cellular-based systems are cell-line dependent and some suffer from serious problems of not properly providing information at physiological levels.

Despite all of the criticisms, the use of in vitro chemical TAC methods is still very popular for technological and nutritional purposes and, although having obvious limitations, valuable information can be extracted and used for technological purposes. ${ }^{52}$

\section{Application of TAC methods to foods: an evolving topic}

Many applications of in vitro antioxidant methods in food research and nutrition have been studied in the last two decades for foods, extracts, beverages and biological samples. In 1994, Serafini et al. ${ }^{53}$ 
introduced the concept of antioxidants for red wine and tea with an emphasis on the association between TAC and the phenolic composition of those matrices. In the same year, Maxwell et al. ${ }^{54}$ associated the TAC of wine with that of the blood of volunteers who consumed red wine.

Subsequently, Yen and Chen ${ }^{55}$ associated the in vitro antioxidant activity and reducing power of tea extracts (Camellia sinensis) with the antimutagenicity against known indirect mutagens. It was concluded that the antioxidant effect of tea extracts was correlated well with the antimutagenicity of teas. Weisburger ${ }^{56}$ explained the mechanisms of action of antioxidants of vegetables and herbal teas. In 2001, Ivanov et $a .^{57}$ assessed the binding effects of red wine antioxidants on human lipoproteins and confirmed that red wine exerted protective effects against both low-density lipoprotein and high-density lipoprotein-induced in vitro oxidation. It was shown that red wine components bind to lipoproteins and protect them from metal ion-dependent and -independent protein and lipid oxidation. From those initial studies onwards, thousands of papers have been published associating a diet rich in antioxidants with the beneficial effects of those substances.

At the beginning of the 2000s, the main objectives were to correlate in vitro, ex vivo and in vivo TAC methods, aiming to reduce the use of animals and to trace the TAC of different foods and agro-industrial by-products.

In this sense, different TAC methods and antioxidants have also been compared in terms of efficacy using in vitro and ex vivo models. For example, Castro et al. ${ }^{58}$ (2006) used three in vitro methods (linoleic acid emulsion, rat brain homogenate and the DPPH test) to correlate the free radical scavenging activity of Trolox and $\alpha$-tocopherol and observed that $\alpha$-tocopherol offered a higher protection of rat brain homogenate and a higher inhibition of DPPH radical than Trolox. Linear correlation analysis showed that the TAC using rat brain homogenate correlated significantly $(P<0.05)$ with the in vitro oxidation of linoleic acid $(r=-0.93)$ and with the inhibition of DPPH radical $(r=-0.99)$. These results showed that in vitro chemical methods may be used as screening methods in place of the use of animals to assess the TAC of antioxidants from food sources.

With the increase of food production, food wastes have increased considerably. Scientists and companies started to serach for sustainable solutions that decrease the waste in the food chain and aggregate value to by-products. Accordingly, seeds, peels, leaves, stalks and many other by-products started to be investigated for their TAC. Wine, fruit juice and other vegetable industries are the main chains that produce a large amount of by-product ${ }^{59-61}$ that have attracted industrial interest for multiple technological applications. In the 1990s, these by-products were not considered to be a rich and potential sources of antioxidant compounds but, over the last 20 years, agro-industrial by-products with recognised TAC have been incorporated into a varied number of foods. ${ }^{62-67}$

Because the research on antioxidants suggested beneficial effects on human health, it moved in a direction that aimed to develop and expand knowledge on the concentrations of antioxidants in food sources: in the 2000s, the era of food antioxidants databases arrived.

\section{THE DEVELOPMENT OF TAC DATABASES OF FOODS}

At the beginning of this century, when chemists were looking for the best method for measuring the TAC in foods and biological fluids, several food TAC databases were developed, aiming to provide tools for epidemiological investigations concerning the health benefits of dietary antioxidants. The first TAC database was published in 2002 by Halvorsen et al. ${ }^{68}$ The database included data on 32 vegetables, 23 fruits, 19 berries, 11 tubers, 18 cereals, ten pulses, six nuts and four dried fruits collected from seven countries measured by the FRAP assay. The results demonstrated that there was more than a 1000-fold difference of TAC values in various dietary plants, with berries being the most antioxidant rich foods. In 2006, it was extended up to 1113 foods obtained from the US Department of Agriculture (USDA) National Food and Nutrient Analysis Program. ${ }^{69}$ The new database included plant and animal products (meat, meat products and substitutes; poultry and poultry products; fish and seafood; and egg and egg dishes), beverages, cooked foods prepared using conventional methods (e.g. microwaving, oven baking, sautéing, boiling and steaming) and composite foods of several brands. Based on typical US serving sizes, blackberries, walnuts, strawberries, artichokes, cranberries, brewed coffee, raspberries, pecan nuts, blueberries, ground cloves, grape juice, red wine and unsweetened baking chocolate were at the top of the ranked list. In 2010, the database was enlarged. ${ }^{70}$ The new database included more than 3100 foods, beverages, spices, herbs and supplements purchased at local stores and markets in Scandinavia, USA and Europe, and from the African, Asian and South American continents. Currently, this is the largest database of TAC values that was further optimised with respect to working on the sample extraction conditions. ${ }^{71}$

In 2004, Wu et al. ${ }^{72}$ measured the TAC using the ORAC test and combining both lipophilic and hydrophilic antioxidant components in over 100 different foods collected from four different regions and during two different seasons in US markets. The database included fruits, vegetables, nuts, dried fruits, spices, cereals and other types of foods. Processing, genetics, season and growing conditions were also taken into account. Lipophilic and hydrophilic extracts were considered, obtaining their ORAC values. Lipophilic ORAC values were $<10 \%$ of the hydrophilic ones, except for some nuts samples. Based on serving size, most of the samples with the highest hydrophilic ORAC value were fruit, particularly berries, whereas avocado had the highest lipophilic ORAC value. In 2007, USDA presented the ORAC of Selected Foods report including 277 food samples. ${ }^{72}$ In 2010, 49 food items were added, including maple syrup, acai, and goji berries, for a total of 326 food items. The database was released on the USDA website. However, in 2012, the USDA Nutrient Data Laboratory removed it as a result of the lack of a direct correspondence of ORAC measurements with physiological activity. Moreover, they realised that ORAC values were misused by manufacturing companies when promoting their products and also by consumers when choosing food and dietary supplements.

During the same years, our group built a TAC database of foods commonly consumed in Italy. Although our database contains few foods compared to the large databases described above, it has some peculiar and value features. We analysed all food items using three different TAC assays and different extraction procedures (i.e. ABTS, FRAP and TRAP assays)..$^{73,74}$ Vegetable oils were directly analysed without any preliminary extraction by the ABTS assay. ${ }^{75}$ Because the grain phytochemicals exist in free, soluble conjugates and insoluble bound forms, ${ }^{76}$ the overall TAC values of cereals extracts were obtained by summing the TAC values of methanol and alkaline hydrolysis extracts. We also used the same approach with other fibre-rich foods (i.e. legumes and nuts). Finally, in 2009, we completed the TAC database by including the effect of the 
major domestic practices (i.e. boiling, pan-frying and deep-frying) on the TAC of commonly consumed cooked vegetables. ${ }^{77}$ The Italian database contains 180 foods, including cereals and cereal based products, nuts, legumes, vegetables and fruit, vegetable oils, spices and herbs, and beverages.

Subsequent to the above described food databases of TAC, several smaller databases were developed and published. Among them, 14 fresh and ten dry fruit, ten roots/tubers and 19 vegetables commonly consumed in India were analysed for their TAC content using two assays (i.e. DDPH and FRAP assays). ${ }^{78,79}$ The hydrophilic ORAC method was used for the TAC analysis of 66 vegetables and 38 fruit commonly consumed in Singapore ${ }^{80,81}$ and 23 vegetables and 13 fruit commonly consumed in Japan. ${ }^{82}$ The hydrophilic and lipophilic ORAC method was used to analyse basic food items, such as fruit, vegetables, grains, legumes, fats/oils and beverages, commonly consumed by the South African population..$^{83}$ In this database, foods were prepared and cooked in accordance with nationally representative recipes. Cultivar and season availability were also considered.

\section{The development of tools for measuring TAC in the diet}

To investigate the relationship between the dietary antioxidant intake and the risk of non-communicable diseases in epidemiological studies, the dietary TAC of subjects has to be measured. To this aim, a food-frequency questionnaire (FFQ) has mainly been used. In the majority of studies, general FFQs validated for recording dietary habits have been applied. However, with the aim of achieving a more precise estimation of the dietary TAC, some FFQs have been specifically developed in groups of a population. In 2007, we specifically designed, developed and validated a semi-quantitative FFQ for the assessment of dietary TAC consisting of 53 questions about the major sources of dietary TAC in Northern Italy. ${ }^{84}$ The questions in the FFQ were referred to a list of 150 foods of the major dietary sources of TAC in the Italian diet obtained by analysing 1125 24-h dietary recalls from the Varese cohort of the European Prospective Investigation into Cancer and Nutrition (EPIC). ${ }^{84}$ The food list was extracted with the aim of covering at least $95 \%$ of the variance of TAC intake and energy intake in the original population. The main contributors to TAC intake were coffee and tea in women and alcoholic beverages in men, followed by fruit and vegetables in both sexes. We also measured plasma TAC by the same methods used for the food TAC (i.e. ABTS and FRAP). Plasma TAC and dietary TAC were not associated, showing that plasma values cannot be used as surrogate measurements for either short- or long-term dietary TAC intake.

The second FFQ was developed and validated in random samples of 108 middle-aged and elderly women (54-73 years old) participating in the population-based Swedish Mammography Cohort. ${ }^{85}$ Reproducibility was studied in 300 women $(56-75$ years old) who completed two FFQ 1 year apart. The dietary TAC was measured by three different assays (i.e. ORAC, TRAP and FRAP) and the FFQ validity was evaluated using the measurement of plasma TAC. The main limitation of the FFQ of Rautiainen et al. ${ }^{85}$ was the exclusion of the coffee contribution in the FFQ because information on coffee was not available in the ORAC database.

Yang et $a l .{ }^{86}$ validated a brief FFQ for the capturing short-term intake of antioxidants related to the previous month in a small sample of US college students (60 subjects). The FFQ contained 70 questions on the major antioxidant sources in the American diet and four additional questions related to supplements. The TAC values of the antioxidant sources were calculated theoretically based on an algorithm developed by the same group. ${ }^{87}$ Theoretical TAC was calculated for each food item as the sum of the product of antioxidant content and antioxidant capacities of individual antioxidants. The FFQ was validated against 30-day food records and plasma antioxidant concentrations. The reliability of the FFQ was evaluated by two FFQ administered at an interval of 1 month. The TAC values from diet and diet and supplements were highly correlated between the FFQ and 30-day food records, whereas neither TAC from diet, nor TAC from diet and supplements was correlated with plasma TAC level. The feasibility in assessing long-term antioxidant intake of the FFQ was later evaluated in 40 overweight postmenopausal women who participated in a 9-month observational study and completed four sets of FFQ and 7-day food record every 3 months. ${ }^{88}$ No significant seasonal variation of antioxidant intakes supports the applicability of this 1-month FFQ with respect to capturing a usual dietary antioxidant pattern for these overweight postmenopausal women.

\section{The application of TAC databases in epidemiological studies}

The described TAC databases have been applied in several epidemiological studies to explore the association between TAC of the diet and the risk of several diseases. Dietary habits were usually recorded by means of a FFQ and the TAC of the diet was calculated by linking the TAC values of individual foods to the food intake data. In the first study, Serafini et al. ${ }^{89}$ found that a high TAC intake from fruit and vegetables (assessed by TRAP) was inversely associated with the risk of both cardia and distal gastric cancer in a case-control study. After that study, which was limited to a TAC database of only 12 food items, a similar approach has been applied several times. A search of PubMed and Scopus database using 'total antioxidant capacity', 'dietary TAC' and 'nonenzymatic antioxidant capacity' in combination with humans, diet, mortality and risks of diseases retrieved more than 50 papers. The majority of them have been published in the last 5 years. The main studies are summarised in Table 1 and are briefly described below.

Three large prospective cohort studies ${ }^{90-92}$ explored the relationship between dietary TAC and total mortality. Only in the PREDIMED study ${ }^{91}$ was no statistically significant relationship found between dietary TAC and mortality, nor for the intake of all the vitamins studied. However, an important reduction (around $80 \%$ ) in the risk of cancer death was reported for those participants who were current smokers and belonged to the third and fourth quintiles of dietary TAC compared to those within the first category. ${ }^{91}$

Regarding cardiovascular disease, the results are contrasting. Some studies reported an inverse association between dietary TAC and myocardial infarction, ${ }^{93}$ heart failure, ${ }^{94}$ hemorrhagic stroke ${ }^{95}$ and ischemic infarction. ${ }^{96,97}$ In other studies, no association was found between TAC intake and the risk of ischemic and hemorrhagic stroke and dementia ${ }^{98}$ and cognitive function ${ }^{99}$ in the elderly.

The role of dietary TAC in protecting against cancer has also been explored, especially in colorectal cancer, with contrasting results being reported. In a prospective study conducted in US males, a high TAC intake from coffee, decaffeinated coffee and tea, but not the total TAC intake, was associated with a reduced rectal cancer risk. ${ }^{100}$ In the Italian segment of EPIC, when colon and rectal cancers were considered separately, an increasing TAC intake was associated with a decreasing risk of colon cancer and an increased risk of rectal cancer. ${ }^{101}$ Conversely, in an Italian multicentre case-control study, a significant inverse association between 
Table 1. Characteristics of the studies in which the association between dietary TAC and the risk of several non-communicable diseases and health outcomes was explored

\begin{tabular}{|c|c|c|c|c|}
\hline $\begin{array}{l}\text { Author, year, } \\
\text { country, design of study }\end{array}$ & Sample size, age & $\begin{array}{l}\text { Assay used/food intake } \\
\text { evaluation tool }\end{array}$ & Outcome & Associations observed \\
\hline $\begin{array}{l}\text { Agudo et al. }{ }^{90}, 2007, \text { Spain } \\
\text { Prospective cohort study }\end{array}$ & $\begin{array}{l}41358 \text { men and women, } \\
30-69 \text { years old }\end{array}$ & $\begin{array}{l}\text { TRAP, FRAP, TEAC, ORAC } \\
\text { with DHQ }\end{array}$ & Mortality & $\begin{array}{l}\text { All of the indicators of TAC, FRAP, } \\
\text { TRAP, TEAC, ORAC from plant } \\
\text { food intake were associated } \\
\text { with a reduced mortality }\end{array}$ \\
\hline $\begin{array}{l}\text { Henriquez Sanchez et al. }{ }^{91} \text {, } \\
\text { 2016, Spain Prospective } \\
\text { cohort study }\end{array}$ & $\begin{array}{l}7447 \text { men and women, } \\
55-80 \text { years old }\end{array}$ & FRAP with 137-item FFQ & Mortality & $\begin{array}{l}\text { No statistically significant } \\
\text { association was found } \\
\text { between dietary TAC and total } \\
\text { mortality in elderly subjects } \\
\text { at high cardiovascular risk }\end{array}$ \\
\hline $\begin{array}{l}\text { Bastide et al. }{ }^{92}, 2017, \text { France } \\
\text { Prospective cohort study }\end{array}$ & $\begin{array}{l}72512 \text { women, middle } \\
\text { age }\end{array}$ & FRAP, TRAP with DHQ & Mortality & $\begin{array}{l}\text { NEAC dietary equivalent intake } \\
\text { was inversely associated with } \\
\text { all-cause, cancer, } \\
\text { cardiovascular disease, and } \\
\text { other disease mortality }\end{array}$ \\
\hline $\begin{array}{l}\text { Rautiainen et al.93, 2012, } \\
\text { Sweden Prospective } \\
\text { cohort study }\end{array}$ & $\begin{array}{l}32561 \text { women, } \\
49-83 \text { years old }\end{array}$ & ORAC with 96-item FFQ & Myocardial infarction & $\begin{array}{l}\text { Higher TAC of diet was } \\
\text { statistically significantly } \\
\text { associated with lower risk of } \\
\text { incident myocardial infarction } \\
\text { in a dose-response manner }\end{array}$ \\
\hline $\begin{array}{l}\text { Rautiainen et al. } .94,2013, \\
\text { Sweden Prospective } \\
\text { cohort study }\end{array}$ & $\begin{array}{l}33713 \text { women, } \\
49-83 \text { years old }\end{array}$ & ORAC with 96-item FFQ & Heart failure & $\begin{array}{l}\text { Higher TAC of diet was } \\
\text { associated with lower risks of } \\
\text { heart failure incidence }\end{array}$ \\
\hline $\begin{array}{l}\text { Rautiainen et al. }{ }^{95}, 2012, \\
\text { Sweden Prospective } \\
\text { cohort study }\end{array}$ & $\begin{array}{l}31035 \text { CVD-free and } \\
5680 \text { with CVD history } \\
\text { at baseline women, } \\
49-83 \text { years old }\end{array}$ & ORAC with 96-item FFQ & Stroke & $\begin{array}{l}\text { Dietary TAC was inversely } \\
\text { associated with total stroke } \\
\text { among CVD-free women and } \\
\text { hemorrhagic stroke among } \\
\text { women with CVD history }\end{array}$ \\
\hline $\begin{array}{l}\text { Del Rio et al. }{ }^{96}, 2011, \text { Italy } \\
\text { Prospective cohort study }\end{array}$ & $\begin{array}{l}41620 \text { men and women, } \\
44-61 \text { years old }\end{array}$ & TEAC with 188-item FFQ & Stroke & $\begin{array}{l}\text { A strong inverse association was } \\
\text { observed between ischemic } \\
\text { stroke, but not hemorrhagic } \\
\text { stroke, and dietary TAC }\end{array}$ \\
\hline $\begin{array}{l}\text { Colarusso et al. }{ }^{97}, 2017 \\
\text { Sweden Prospective } \\
\text { cohort study }\end{array}$ & $\begin{array}{l}34555 \text { men and women, } \\
33-65 \text { years old }\end{array}$ & FRAP with 85-item FFQ & Stroke & $\begin{array}{l}\text { Dietary NEAC intake was } \\
\text { associated with a reduced } \\
\text { incidence of stroke, more } \\
\text { specifically ischemic stroke, in } \\
\text { women }\end{array}$ \\
\hline $\begin{array}{l}\text { Devore et al. }{ }^{98}, 2013, \text { The } \\
\text { Netherlands Prospective } \\
\text { cohort study }\end{array}$ & $\begin{array}{l}5395 \text { men and women, } \\
>55 \text { years old }\end{array}$ & FRAP with 170 -item FFQ & Dementia and stroke & $\begin{array}{l}\text { TAC of the diet was not related } \\
\text { to a reduced risk of dementia } \\
\text { or stroke }\end{array}$ \\
\hline $\begin{array}{l}\text { Devore et al. }{ }^{99}, 2010, \text { United } \\
\text { States Prospective cohort } \\
\text { study }\end{array}$ & $\begin{array}{l}16010 \text { women, } \\
>70 \text { years old }\end{array}$ & FRAP with 61-item FFQ & Cognitive function & $\begin{array}{l}\text { No clear evidence of a } \\
\text { consistent association } \\
\text { between TAC of diet and } \\
\text { cognition }\end{array}$ \\
\hline $\begin{array}{l}\text { Mekary et al. }{ }^{100}, 2010, \\
\text { United States Prospective } \\
\text { cohort study }\end{array}$ & $\begin{array}{l}47339 \text { men, } 40-75 \text { years } \\
\text { old }\end{array}$ & FRAP with 131-item FFQ & Colorectal cancer & $\begin{array}{l}\text { Dietary total TAC intakes were } \\
\text { not associated with colorectal } \\
\text { and colon cancer risk, } \\
\text { whereas an inverse } \\
\text { association between dietary } \\
\text { TAC intake and rectal cancer } \\
\text { risk limited to TAC intake from } \\
\text { coffee, decaffeinated coffee, } \\
\text { and tea combined was } \\
\text { observed }\end{array}$ \\
\hline $\begin{array}{l}\text { Vece et al. }{ }^{101}, 2015, \text { Italy } \\
\text { Prospective cohort study }\end{array}$ & $\begin{array}{l}45194 \text { men and women, } \\
42-60 \text { years old }\end{array}$ & TEAC with 188 item- FFQ & Colorectal Cancer & $\begin{array}{l}\text { No association between dietary } \\
\text { TAC and overall risk of } \\
\text { colorectal cancer. However, } \\
\text { increasing TAC intake was } \\
\text { associated with reducing risk } \\
\text { of colon cancer and } \\
\text { increasing risk of rectal } \\
\text { cancer, both with significant } \\
\text { trends }\end{array}$ \\
\hline
\end{tabular}




\section{Table 1. Continued}

\begin{tabular}{|c|c|c|c|c|}
\hline $\begin{array}{l}\text { Author, year, } \\
\text { country, design of study }\end{array}$ & Sample size, age & $\begin{array}{l}\text { Assay used/food intake } \\
\text { evaluation tool }\end{array}$ & Outcome & Associations observed \\
\hline $\begin{array}{l}\text { La Vecchia et al. }{ }^{102}, 2013, \\
\text { Italy Case-control } \\
\text { study }\end{array}$ & $\begin{array}{l}1953 \text { cases and } 4154 \\
\text { controls }\end{array}$ & $\begin{array}{l}\text { TEAC, FRAP, TRAP with } \\
\text { 83-item FFQ }\end{array}$ & Colorectal cancer & $\begin{array}{l}\text { Dietary TAC was inversely } \\
\text { related to the risk of } \\
\text { colorectal cancer and } \\
\text { associations were somewhat } \\
\text { stronger for rectal cancer }\end{array}$ \\
\hline $\begin{array}{l}\text { Vance et al. }{ }^{103}, 2016, \\
\text { United States } \\
\text { Prospective cohort } \\
\text { study }\end{array}$ & $\begin{array}{l}2000 \text { men, } 40-79 \text { years } \\
\text { old }\end{array}$ & TEAC with DHQ & Prostate cancer & $\begin{array}{l}\text { TAC from diet and supplements } \\
\text { combined was associated } \\
\text { with a reduced odds of high } \\
\text { aggressive prostate cancer }\end{array}$ \\
\hline $\begin{array}{l}\text { Zamora-Ros et al. }{ }^{104} \\
\text { 2013, Western } \\
\text { European countries }^{\text {a }} \\
\text { Prospective cohort } \\
\text { study }\end{array}$ & $\begin{array}{l}477206 \text { men and } \\
\text { women, } 35-70 \text { years } \\
\text { old }\end{array}$ & FRAP, TRAP with FFQs & Hepatocellular cancer & $\begin{array}{l}\text { Dietary NEAC was inversely } \\
\text { associated with } \\
\text { hepatocellular cancer, but } \\
\text { statistical significance was } \\
\text { lost after exclusion of the first } \\
2 \text { years of follow-up }\end{array}$ \\
\hline $\begin{array}{l}\text { Lucas et al. }{ }^{105}, 2016, \text { Italy } \\
\text { Case-control study }\end{array}$ & $\begin{array}{l}326 \text { cases and } 652 \\
\text { controls, } 34-85 \text { years } \\
\text { old }\end{array}$ & $\begin{array}{l}\text { TEAC, FRAP with 83-item } \\
\text { FFQ }\end{array}$ & Pancreatic cancer & $\begin{array}{l}\text { Dietary TAC was associated with } \\
\text { a decreased pancreatic cancer } \\
\text { risk }\end{array}$ \\
\hline $\begin{array}{l}\text { Pantavos et al. }{ }^{106}, 2015, \\
\text { The Netherlands } \\
\text { Prospective cohort } \\
\text { study }\end{array}$ & $\begin{array}{l}3209 \text { men and women, } \\
\text { > } 55 \text { years old }\end{array}$ & FRAP with 170-item FFQ & Breast cancer & $\begin{array}{l}\text { High overall dietary TAC is } \\
\text { associated with a lower risk of } \\
\text { breast cancer }\end{array}$ \\
\hline $\begin{array}{l}\text { Gifkins et al. }{ }^{107}, 2012, \\
\text { United States } \\
\text { Case-control study }\end{array}$ & $\begin{array}{l}417 \text { cases and } 395 \\
\text { controls, }>21 \text { years } \\
\text { old }\end{array}$ & $\begin{array}{l}\text { ORAC, FRAP with } \\
\text { 110-item FFQ }\end{array}$ & Endometrial cancer & $\begin{array}{l}\text { No association between dietary } \\
\text { TAC and risk of endometrial } \\
\text { cancer }\end{array}$ \\
\hline $\begin{array}{l}\text { Gifkins et al. }{ }^{108}, 2012, \\
\text { United States } \\
\text { Case-control study }\end{array}$ & $\begin{array}{l}205 \text { cases and } 391 \\
\text { controls, > } 21 \text { years } \\
\text { old }\end{array}$ & $\begin{array}{l}\text { ORAC, FRAP with } \\
\text { 110-item FFQ }\end{array}$ & Epithelial ovarian cancer & $\begin{array}{l}\text { Little evidence that the dietary } \\
\text { TAC had an impact on ovarian } \\
\text { cancer risk }\end{array}$ \\
\hline $\begin{array}{l}\text { Rossi et al. }{ }^{109}, 2016 \text {, Italy } \\
\text { Case-control study }\end{array}$ & $\begin{array}{l}454 \text { cases and } 908 \\
\text { controls, } 18-79 \text { years } \\
\text { old }\end{array}$ & $\begin{array}{l}\text { FRAP, TEAC, TRAP with } \\
\text { 83-item FFQ }\end{array}$ & Endometrial cancer & $\begin{array}{l}\text { Dietary TAC was inversely } \\
\text { related to endometrial cancer } \\
\text { risk for all the TAC used } \\
\text { methods, but decreased } \\
\text { when considering TAC } \\
\text { without the contribution of } \\
\text { coffee }\end{array}$ \\
\hline $\begin{array}{l}\text { Mancini et al. }{ }^{110}, 2018, \\
\text { France Prospective } \\
\text { cohort study }\end{array}$ & $\begin{array}{l}64223 \text { women, } \\
44-58 \text { years old }\end{array}$ & FRAP with 208-item FFQ & Type 2 diabetes & $\begin{array}{l}\text { A higher total TAC of the diet, } \\
\text { measured excluding the } \\
\text { contribution of coffee, was } \\
\text { associated with a lower risk of } \\
\text { type } 2 \text { diabetes }\end{array}$ \\
\hline $\begin{array}{l}\text { Okubo et al. }{ }^{111}, 2014, \text { UK } \\
\text { Prospective cohort } \\
\text { study }\end{array}$ & $\begin{array}{l}2694 \text { men and women, } \\
59-73 \text { years old }\end{array}$ & $\begin{array}{c}\text { ORAC, FRAP, TRAP, TEAC } \\
\text { with 129-item FFQ }\end{array}$ & $\begin{array}{l}\text { Diabetes markers } \\
\text { (fasting and 120-min } \\
\text { plasma glucose and } \\
\text { insulin, HOMA-IR) }\end{array}$ & $\begin{array}{l}\text { In men, dietary TAC estimated } \\
\text { by all four assays was } \\
\text { inversely associated with } \\
\text { fasting insulin concentration } \\
\text { and HOMA-IR. With the } \\
\text { exception of ORAC, dietary } \\
\text { TAC was also inversely related } \\
\text { to } 120 \text {-min glucose } \\
\text { concentration. In women, } \\
\text { dietary TAC estimated by all } \\
\text { assays showed consistent } \\
\text { inverse associations with } \\
\text { fasting and } 120 \text {-min glucose } \\
\text { and insulin concentrations } \\
\text { and HOMA-IR }\end{array}$ \\
\hline $\begin{array}{l}\text { Psaltopoulou et al. }{ }^{112} \text {, } \\
\text { 2011, Greece } \\
\text { Prospective cohort } \\
\text { study }\end{array}$ & $\begin{array}{l}\text { 1,1018 men and women, } \\
\text { men } 41 \pm 11 \text { years old } \\
\text { and women } \\
38 \pm 11 \text { years old }\end{array}$ & $\begin{array}{l}\text { FRAP, TRAP, TEAC with } \\
\text { 190-item FFQ } \\
\text { adherence to the } \\
\text { Mediterranean diet } \\
\text { with the } \\
\text { Med-DietScore }\end{array}$ & $\begin{array}{l}\text { Diabetes markers } \\
\text { (fasting glucose and } \\
\text { insulin, HOMA-IR) }\end{array}$ & $\begin{array}{l}\text { Inverse, age-energy adjusted } \\
\text { correlations were observed } \\
\text { between all three assays of } \\
\text { TAC and log-glucose, } \\
\text { log-insulin and log-HOMA-IR } \\
\text { concentration. Multi-adjusted } \\
\text { analysis confirmed the } \\
\text { previous relationships only } \\
\text { among participants who were } \\
\text { not on the Mediterranean } \\
\text { dietary pattern }\end{array}$ \\
\hline
\end{tabular}


Table 1. Continued

Author, year, country, design of study

Bahadoran et al. ${ }^{113}$, 2012, Iran Prospective $\quad 19-70$ years old cohort study

Assay used/food intake evaluation tool

Outcome

ORAC with 168-item FFQ glucose, TG, HDL-cholesterol, blood pressure, abdominal obesity)

\author{
Hermsdorff et al. ${ }^{114}$ \\ 2011, Brazil \\ Cross-sectional study
}

266 men and women, 18-35 years old

Puchau et al. ${ }^{115}, 2010$, study

50 men and women $20.8 \pm 2.7$ years old

Kim et al. ${ }^{116}$, 2016, Unites 4039 men and women, States Cross-sectional >19years old study Spain Cross-sectional
FRAP with 3-day weighed food record and 136-item FFQ

FRAP with 3-day weighed food record and 136-item FFQ

TAC theoretically calculated $^{87}$ with $24-\mathrm{h}$ dietary recalls
Adiposity, metabolic and oxidative stress markers

MetS components (fasting glucose, TG, HDL-cholesterol, free fatty acids, homocysteine, blood pressure, abdominal obesity)

CVD risk factors (waist circumference, blood pressure, TG, HDL-cholesterol, total cholesterol, hs-CRP fasting glucose and insulin, HOMA-IR)

Brighenti et al. $^{117}$, 2005, 243 men and women, Italy Cross-sectional $\quad 60.1 \pm 7.0$ years old study

Wang et al. ${ }^{118}, 2014$, United States 9-month women, $40-70$ years observational study

\section{TEAC with 3-day weighed food record} old
Inflammatory markers (hs-CRP, adhesion molecule-1)

Inflammatory markers (hs-CRP, TNF- $\alpha$, MCP-1, vascular cell adhesion molecule 1, intercellular adhesion molecule-1, adiponectin, E-selectin)

Inflammatory marker (hs-CRP)

Inflammatory markers (adiponectin, hs-CRP, TNF- $\alpha$ ) $38 \pm 12$ years old

\section{AC theoretically
calculated $^{87}$ with \\ 7-day food record} men $40 \pm 11$ years old 190-item FFQ and women

RAP TEAC, ORAC, TRAP FRAP, TEAC, TRAP with

2010, Greece Cross-sectional study old
Svilaas et al. ${ }^{121}, 2004$, Norway Cross-sectional study

Valtuena et al. $^{122}$, 2007, Italy Cross-sectional study
61 men and women, $57.8 \pm 9.4$ years old

247 men and women, 60 TEAC with 3-day (8) years old
FRAP with 7-d weighed dietary record weighed food record
Plasma carotenoids

Plasma carotenoids
Associations observed
An inverse association between dietary TAC and the MetS components at the baseline examination was observed. After a 3-year follow-up, in individuals who had higher dietary TAC was also observed a lower occurrence of abdominal obesity and a lower weight and abdominal fat gain

Dietary TAC was inversely associated with glucose and lipid biomarkers, waist circumference values as well as to lower mild central obesity occurrence in healthy young adults

Systolic blood pressure, serum glucose, and free fatty acids were negatively associated with dietary TAC independently of sex and daily energy intake

Dietary TAC was associated with reduced blood CVD risk factors. Both greater TAC from diet and TAC from diet and supplements were associated with reduced blood TG, TG/HDL-C ratio, hs-CRP, and increased $\mathrm{HDL}-\mathrm{C}$ after adjusting for all covariates

A strong inverse association was observed between TAC intake and plasma levels of hs-CRP. The relationship was stronger for subjects with hypertension than normotensive individuals

At baseline, subjects consuming diets with high dietary TAC had lower levels of plasma hs-CRP and MCP-1 compared with those with low dietary TAC. Change in dietary TAC was inversely associated with plasma CRP levels over a 9-month period

Dietary TAC was inversely associated with serum hs-CRP concentration regardless of assay

Positive associations were observed between dietary antioxidant capacity in terms of FRAP, TRAP and TEAC on adiponectin concentrations. One mmol day ${ }^{-1}$ change in dietary antioxidant capacity was related to $\sim 1 \mu \mathrm{g} \mathrm{mL}^{-1}$ change in adiponectin levels

The intake of TAC was significantly correlated with plasma lutein, zeaxanthin, and lycopene

Dietary TAC significantly increased with increasing plasma b-carotene, especially in moderate alcohol drinkers

a European Prospective Investigation into Cancer and Nutrition study.

CVD, cardiovascular disease; $\mathrm{DHQ}$, dietary history questionnaire; FFQ, food frequency questionnaire; $F R A P$, ferric reducing antioxidant potential; $\mathrm{HDL}$, high density lipoproteins; HOMA-IR, homeostatic model assessment of insulin resistance; hs-CRP, C-reactive protein; MCP-1, monocyte chemoattractant protein-1; MetS, metabolic syndrome; NEAC, non-enzymatic antioxidant capacity; ORAC, oxygen radical antioxidant capacity; TAC, total antioxidant capacity; TEAC, Trolox equivalent antioxidant capacity; TG, triglyceride; TNF- $\alpha$, tumor necrosis factor- $\alpha$; TRAP, total radical-trapping antioxidant parameter. 
TAC and colorectal cancer risk was found. ${ }^{102}$ The overlap of TAC intake with dietary fibre intake might be an important confounding factor with respect to the reduction of colon cancer risk.

The relationship between dietary TAC and other cancer risks has been explored mainly in population-based case-control studies. Dietary TAC was reported to be protective in prostate cancer, ${ }^{103}$ hepatocellular cancer ${ }^{104}$ (even though the statistical significance was attenuated after exclusion of the first 2 years of follow-up), pancreatic cancer ${ }^{105}$ and breast cancer. ${ }^{106}$ Conversely, in other studies, the association was null between dietary TAC and endometrial cancer ${ }^{107}$ or limited between dietary TAC and endometrial and ovarian cancer. ${ }^{108,109}$

To date, only one study has recently investigated the association between dietary TAC and risk of type 2 diabetes. ${ }^{110}$ This finding is consistent with studies reporting that a higher dietary TAC was associated with a better glucose tolerance in older men and women, ${ }^{111}$ and correlated with lower levels of glycaemic indices in healthy individuals, as well as in pre-diabetic and diabetic ones. ${ }^{112}$ However, in the latter study, the correlation persisted only in those who, although having a high antioxidant intake, scored low in the Mediterranean diet scale used, suggesting that those who exhibit an unhealthy dietary pattern could benefit from guidance to foods with antioxidant potential. ${ }^{112}$

Studies have also reported that dietary TAC is inversely associated with the occurrence of several metabolic syndrome (MetS) components ${ }^{113-115}$ and cardiovascular disease risk factors. ${ }^{115,116}$ Several studies have also explored the relationship between C-reactive protein (CRP), a marker of systemic inflammation associated with cardiovascular disease, type 2 diabetes and cancer, and dietary TAC. The first study was carried out by our group. ${ }^{117}$ We found a strong inverse association between energy-adjusted dietary TAC and plasma levels of CRP in 243 non-diabetic subjects. Such an association was stronger for subjects with hypertension than normotensive individuals. Similar inverse associations were observed in overweight/obese postmenopausal women ${ }^{118}$ and in young Japanese women. ${ }^{119}$ Along with CRP, dietary TAC affected adiponectin, an adipose tissue-released hormone-like protein, in free-living, apparently healthy adults from the ATTICA study ${ }^{120}$ and the plasma carotenoids in two cross-sectional studies. ${ }^{121,122}$

TAC measurement has been strongly criticised, 6,7 However, although further studies are needed to support these epidemiological findings, the evidence briefly summarised here could be of significance when validating the use of TAC for foods and describing the quality of a diet. Accordingly, Puchau et al. ${ }^{123}$ found a positive significant association between dietary TAC of 153 healthy participants and several nutritional quality indices, such as the Mediterranean Diet Score and Healthy Eating Index.

\section{THE APPLICATION OF TAC METHODS TO BIOLOGICAL FLUIDS}

The major role of oxidative stress in ageing and the development of many diseases is firmly established, ${ }^{124-129}$ highlighting the need to measure oxidative stress in vivo. ${ }^{130}$ To obtain a complete understanding of the oxidative processes in biological systems, other tools beside TAC should be measured.

Beside the direct quantification of ROS and RNS in biological systems, an indirect approach can be used to measure compounds generated by their action on cell substrates. The first group of molecules includes lipid oxidation products (such as MDA, 4-hydroxy-2-nonenal, F2-isoprostanes, and prostaglandin F2 $\alpha$ ), markers of DNA oxidation (including 7,8-dihydroxy-8-oxo-2'-deoxyguanosine and etheno-DNA adducts) and modified proteins (including carbonylated, nitrosilated, oxidised at cysteine residues as Keap1, etc.). The second group is made by antioxidant enzymes, which act as ROS scavengers [such as superoxide dismutase (SOD), catalase and glutathione peroxidase], as well as non-enzymatic molecules, which include endogenous (such as uric acid, bilirubin and thiols) and dietary compounds (such as tocopherols, ascorbic acid, carotenoids and phenolics). ${ }^{130}$

\section{Correlation between plasma TAC and the consumption of antioxidant rich-foods}

The first real evidence of a correlation between individual plasma TAC and diet dates back to 24 years ago and involves the studies of Maxwell et al. ${ }^{54}$ and of Serafini et al..$^{53}$ In both studies, the ability of red wine (at a dose of $5.7 \mathrm{~mL} \mathrm{~kg}^{-1}$ ) and of green and black tea $(300 \mathrm{~mL})$ was shown to increase plasma TEAC and TRAP, respectively (peaking within 30 and 100 min from consumption) in healthy subjects. However, in the same year, although Serafini et al. ${ }^{131}$ found that the addition of milk to $300 \mathrm{~mL}$ of black and green tea abolished the increase of plasma TAC caused by the sole tea, Maxwell and Thorpe ${ }^{132}$ reported that $500 \mathrm{~mL}$ of English breakfast tea did not change post-prandial plasma TAC in healthy subjects. Those studies, although pioneering, already showed that the association between TAC and antioxidant-rich food consumption was not so obvious and that analytical approaches, as well as foods and individual related factors, might influence the plasma TAC measurement.

Subsequently, more complex investigations, including acute and chronic interventions with beverages, solid foods and supplements, focusing on both serum and urine antioxidant capacity, have been carried out. Investigations by Cao et al. ${ }^{133,134}$ found that the overall antioxidant capacity measured by ORAC and FRAP (but not TEAC) in the serum or urine of eight elderly women was significantly increased over $4 \mathrm{~h}$ after the consumption of strawberries $(240 \mathrm{~g})$, spinach $(294 \mathrm{~g})$, red wine $(300 \mathrm{~mL})$ or vitamin C (1250 mg). This finding was independent of the potential effect of antioxidant proteins in plasma (because ORAC was performed on deproteinized samples and FRAP was not influenced by proteins), although a contribution of uric acid ranging from $36 \%$ to $44 \%$ was calculated in the cases of strawberries and spinach treatments with respect to both ORAC and FRAP data. ${ }^{134} \mathrm{~A}$ few months later, the same study group showed that a rise of plasma ORAC also occurred in 36 fasting subjects who had been consuming (over the previous 4 weeks) a diet providing ten servings of fruits and vegetables. ${ }^{133}$ Independently, Miller et al. ${ }^{135}$ found a reduced lipid peroxidation (breath ethane) in 42 healthy subjects who were consuming (daily) nine servings of fruit and vegetables for 8 weeks compared to subjects consuming four servings. The reduced lipid oxidation was associated with increased serum levels of some carotenoids ( $\beta$-carotene, cryptoxanthin and zeaxanthin) and a trend towards a higher plasma ORAC. ${ }^{135}$

Other studies showed that single antioxidants, foods or combinations of antioxidant supplements failed to significantly change TAC of plasma, despite an increase of some antioxidant enzymes sometimes being observed. ${ }^{136-141}$ Currently, the debate about the effect of food consumption on plasma TAC and its physiological validity is still active.

Thus, a few years after the initial evidence was obtained, discrepant findings on the effects of antioxidant-rich beverages and foods on plasma TAC had already been found and the criticisms 


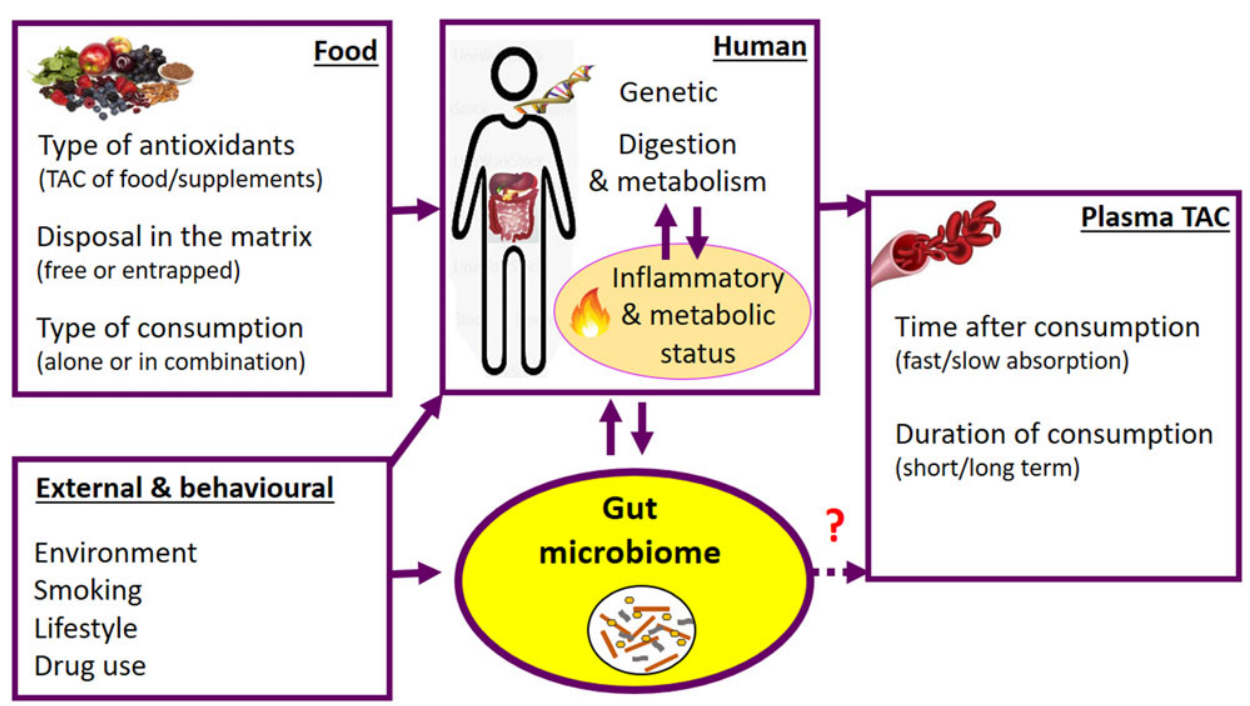

Figure 1. Factors influencing plasma TAC in humans.

and limitations of a plasma TAC-based approach with respect to validating the effect of antioxidant-rich foods were being raised in the literature. Over the years, many studies contributed toward undestanding the reasons for the discrepancies among the studies, as well as the limitations with respect to measuring plasma TAC

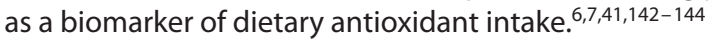

The incongruence of results between the different assays in the same plasma samples collected from patients or healthy subjects after supplementation with antioxidant rich foods strongly highlighted the methodological and biological limitations of TAC measurement with respect to biological fluids.

There is general consensus that the main limitations include:

- The different sensitivity of assays for the various antioxidants present in biological fluids;

- The different correlations of biological TAC with the dietary TAC as a consequence of the possible influence of other antioxidant compounds in biological fluids (such as proteins for ORAC or uric acid for FRAP);

- The incomplete reliability of the understanding of individual antioxidant status given by TAC assays as a result of the neglected contribution of the antioxidant enzymes and the consequent need to interpret with caution the results indicating small changes of TAC.

In addition to the points oulined above, possibly the strongest limitation of plasma TAC is related to the biological significance and interpretation of the results when defining the contribution of the foods/diets with respect to the changes observed in humans after food consumption. Such a limitation is discussed further below.

\section{The biological relevance of an increased plasma TAC}

To establish the biological relevance of plasma TAC, an understanding of the reasons behind the variability of the human TAC response to diet is fundamental. Figure 1 shows the physiological and external factors influencing (or that are assumed to influence) plasma TAC in humans.

Plasma TAC is the combined result of dietary habits, environmental and behavioural factors combined with the specific physiological conditions of each subject.
The chemical structures, the disposition of antioxidant molecules in the food matrix or supplements (i.e. free, glycosylated, polymerised or chemically bound to other food components) and the method of consumption of the antioxidant compounds (i.e. alone or combined with other foods) could influence the pharmacokinetic parameters. The bioavailability of dietary antioxidant compounds results from the fine mechanisms of digestion, absorption and metabolism occurring in the human body, thus playing a key role in the biological effects of the dietary compounds, including plasma TAC. Thus, the huge inter-individual variability in those mechanisms can easily explain the variability of the plasma TAC response to one food/supplement.

Individual genetics, as well as baseline inflammatory and antioxidant status, are also central factors. Wang et al. ${ }^{145}$ demonstrated that more than $50 \%$ of the phenotypic variance in plasma TAC in humans has a genetic component. In other words, specific traits of DNA are selectively down- or up-regulated by the environment, the diet or other unknown stimuli, and tune TAC in humans. Interestingly, the genetic contribution to plasma TAC variability was found to be greater in smokers compared to non-smokers ( $83 \%$ versus $49 \%$, respectively). ${ }^{145}$

Such an observation could be related to the cellular and systemic homeostatic control of oxidative status. The major cellular defense mechanism against oxidative stress is the Nrf2 system, which activates antioxidant enzymes (GST, SOD) via induction of the antioxidant response element by a variety of bioactive dietary compounds. ${ }^{146-148}$ Thus, the genetic capacity of individuals to maintain the redox status in cells could impact both inflammatory status and systemic oxidative status, as well as the susceptibility of the individual to oxidative stress and recovery from that condition. In general, the evidence shows that plasma TAC is more prone to increase after an antioxidant-rich food challenge in subjects with a mild oxidative stress, such as smokers, overweight/obese and diabetic subjects compared to non-smokers or normal weight or healthy subjects, respectively. ${ }^{149}$ It appears that, under conditions of oxidative stress, when the endogenous control of oxidative status is unbalanced because of the depletion of antioxidant enzymes and plasma reservoirs of uric acid, vitamin C, vitamin $\mathrm{E}$ and protein thiols, the body becomes more susceptible to the dietary antioxidant. This explanation is mainly consistent with the findings from short-term studies, whereas, over the long term, 
other factors may occur that induce cellular antioxidant responses, dimming the direct connection between diet and plasma TAC.

This scenario is in line with the recent evidence concerning the role of the gut microbiota in human physiological mechanisms. Over the last decade, growing evidence has shown that the human gut microbiome, including the composition of bacteria living in human gut, as well as their genes and activities, plays a key role in human health and in the metabolic response to diet. ${ }^{150}$ The communities of microbes harbouring the gut influence the metabolism of macro- and micro-nutrients arriving at the colon, as well as their systemic effects, by modulating the production of specific short chain fatty acids, vitamins, metabolites and mediators of immunity (e.g. AhR ligands). ${ }^{151}$ Conversely, diet may modify gut microbiota composition and function over time, thus possibly modulating the inflammatory and metabolic status of individuals and, as a consequence, their digestive and metabolic processes, in addition to the redox status.

The well-known implications of the gut microbiome regarding individual health status have led to a wide consensus among food scientists, physiologists and microbiologists with respect to a need for well conducted randomised controlled trials aiming to establish the causative role of gut microbiota in relation to diet-related disease, possibly identifying a dietary strategy for shaping healthy gut microbiota. ${ }^{152}$

Although the indirect action of gut microbiota on plasma TAC is logical, only three recent dietary intervention studies in humans have been performed to explore this field by considering both gut microbiota and serum TAC. ${ }^{153-155}$ Two studies involved pregnant women with gestational diabetes mellitus and showed that a 6-week supplementation of a probiotic or a synbiotic increased serum TAC and ameliorated the cholesterol profile compared to a placebo. ${ }^{153,154}$ One study involved diabetic hemodialysis patients and showed that probiotic supplementation for 12 weeks had beneficial effects on markers of glucose homeostasis, inflammation and oxidative stress (measured as plasma TAC). ${ }^{155}$

In this respect, more effort is need toward establishing whether there is a direct connection between an abundance of specific bacterial species in the gut and plasma TAC or whether only an indirect interplay mediated by inflammatory and metabolic status occurs. This result may be achieved by a deeper analysis of data concerning the abundance of bacterial species in the feces, as well as of plasma TAC and metabolic/inflammatory parameters from human studies, finalised to individual associations between microbial and health outcomes in the general population under investigation or in subgroups of individuals categorised for age, gender, nutritional, metabolic or inflammatory status.

Plasma TAC cannot be considered as a unique biomarker of individual antioxidant status because it is influenced by too many factors (physiological of individuals and environmental) and because it is subjected to homeostatic control. However, the combined evaluation of plasma TAC with other markers of individual metabolism, inflammation, genetics and health (such as circulating dietary biomarkers, biomarkers of inflammation, biomarkers of gut microbial activity and gut microbiota composition) could lead in the future to the characterisation of people who respond in a different way to foods/diets with a high-TAC versus a low TAC. Such an approach would provide multiple benefits. From a perspective of basic research, it would clarify the influence of homeostatic oxidative control on plasma TAC values. From a perspective of personalised nutrition, it would allow the characterisation of a population who may benefit from a nutritional approach based on dietary antioxidants. From a perspective of food design, it would help to individually identify the best physiological target for foods that are intended to modulate individual antioxidant status.

\section{WHAT WENT WRONG WITH TAC MEASUREMENT?}

As highlighted above, the measurement of antioxidant capacity both in foods and in vivo has been very useful in a variety of different fields. ${ }^{52}$ Straightforward results in food have been obtained with respect to assessing the effects of processing on the overall balance of pro and antioxidant phenomena occurring during food thermal treatments, refining, formulation, etc. The recent possibility of also measuring the insoluble material provided a decisive contribution toward obtaining an overall understanding of TAC modifications in foods. ${ }^{39}$ Indeed, changes in food solubility (i.e. the extraction efficacy) are likely responsible for many changes of the antioxidant activities reported in the literature ${ }^{156}$; thus, monitoring both soluble and insoluble TAC in a single measure, as occurs with the QUENCHER procedure, ${ }^{39}$ may be crucial for a complete understanding. The striking epidemiological evidence connecting TAC intake and disease risks and also the usefulness of a TAC database for characterising the dietary pattern together comprise fundamental positive contributions brought about by research concerning TAC measurement.

Despite these achievements, in recent years, the feeling that the TAC measurement is obsolete and does not provide a relevant contribution to food science advancement has become stronger. Many critical papers dealing with the actual meaning of this measurement have been published questioning the need to report TAC data in the future. ${ }^{6,7}$ This line of thinking, strongly criticising the conclusions obtained in papers using the TAC measurements, is based on two main observations:

1 In many papers, a parallelism between a high food TAC and the potential beneficial physiological effects associated with its consumption has been made. ${ }^{157}$ In other words, berries are healthier than zucchini because their TAC is higher. Goji berries have a higher TAC than strawberries and can be named and sold as 'superfood'. This simplistic approach is obviously not acceptable from the scientific perspective and elicited a strong reaction against the use of TAC measurements.

2 Many efforts have been devoted to develop in vitro antioxidant methods that are more relevant from the physiological standpoint. The use of biological probes (instead of chemical ones) and the adoption of protocols considering both kinetic and thermodynamic aspects have been proposed. Although these approaches provide undisputable advances, any in vitro methods cannot completely mimic the in vivo phenomena and the action of antioxidant compounds within human body. Too many factors related to bioavailability, biotransformation, distribution of organs, oxygen concentration in the different districts and the simultaneous presence of endogenous antioxidants can interact and cannot all be simultaneously incorporated into an in vitro assay. Therefore, the physiological relevance of TAC measurement can be easily criticised and only weak conclusions on the healthy benefits of foods/diet can be made based on the exclusive TAC measurement. ${ }^{142}$

Despite all these limitations, it would be an oversimplification to conclude that TAC measurement is intrinsically useless. Similarly, although compelling evidence based on the TAC database described above showed that TAC dietary intake is associated with 
Table 2. The main advantages and disadvantages of using the TAC measurement are summarised

Pros

TAC provides the complete picture in one simple measure, which can be automated if needed

TAC is a cheap and easy measure providing a preliminary indication in large screenings with thousands of samples

The availability of a TAC database can provide a quick reference for in vivo study, as well for the efficacy of a breeding program

Indications on the bioaccessibility and matrix structure can be obtained by TAC measurements on insoluble material

The in vivo TAC value can be a preliminary indication of pathological conditions

TAC is a useful parameter for monitoring intervention trials on subjects with inflammatory conditions
Cons

The absolute quantification of single antioxidant compounds obtained by metabolomics provides a certain reference for inter-laboratory comparison

TAC is a vague measure: many factors not related to the concentration of antioxidant compounds can interfere with the measurement (e.g. metal)

Inter-laboratory comparisons are very difficult and highly dependent on the extraction procedure

Different measurement methodologies provide completely different results: this is misleading for both scientists and consumers

Relevant modifications in the chemical compositions both among varieties or induced by processing are not captured by TAC measurements

In healthy subjects, there is no correlation between TAC dietary intake and in vivo TAC the prevention of some pathologies, it is useful to remember that, both in food and in vivo, it is absolutely not desirable to increase the TAC above a certain level. 'The more the better' does not work for antioxidant activity, as well as for any other bioactive molecules. Many antioxidant molecules become pro-oxidant at a high concentration ${ }^{158}$ and the negative effect of beta-carotene supplementation in smokers provided a famous example in this respect. ${ }^{159}$

Concerning the methodological aspects of TAC measurements, the recommendation of using different methods for TAC assessment based on different principles has been made and has been followed in many studies. On the other hand, the main advantage of TAC measurements is to provide a simple and straightforward measurement indicating a general feature of a food product or on modifications during processing/shelf life, or on the overall balance of a living cell, tissue and organism.

In this vein, one TAC measurement is probably preferable in most cases. To overload papers with TAC data obtained using different methodologies, often producing discrepant results, will increase the level of confusion rather than provide clarity.

An important distinction should be made between the measurement of total phenolic compounds and that of TAC. The former, usually performed by Folin-Ciocalteu's reagent, is conceptually wrong: that reagent can indeed react with all the reducing agents present in the extract and so it cannot be used as an indication of the amount of phenolic compounds present in a certain food. The value measured using this method can be correlated with the real one in beverages that are particularly rich in phenolic compounds, although this is not the case in many other foods. On the other hand, the TAC value is by definition an estimation of an activity and so it never implies or suggests a direct correlation with the concentration of single food components. The results are often provided as the TEAC (ie, Trolox equivalent antioxidant capacity) and the word 'equivalent' clearly means that there is no the attempt to quantify specific compounds present in the foods.

\section{TAC measurements: pro and cons in the metabolomic era}

Twenty-five years ago, the quantification of single compounds in a complex food matrix was not available to most food scientists and the TAC measurement was a simple and versatile tool for obtaining meaningful information about the quality of raw materials, the effect of processing and behaviour during shelf-life.
Currently, the metabolomic platform allows the quantification of thousands of compounds at relatively low costs and the identified compounds can be correlated with the specific biological significance. Therefore, questions about the usefulness of measuring TAC at the present time are very appropriate. Would not it be better to focus only on the absolute concentrations of all the bioactive (often also antioxidant) compounds present in a food measured with advanced analytical methodologies?

The main advantages and disadvantages of using the TAC measurements in scientific studies are summarised in Table 2. It is clearly shown that it is not reasonable to blame or exalt the TAC measurement as such. The measurement of antioxidant capacity is a tool and, as is the case for all tools, it can be used in both smart or not so smart ways depending on the context of the specific research.

It is important to remember that the main difficulty faced in the 'omic' era is the distillation of relevant information from the enormous amount of data obtained via various high throughput technologies. The massive use of statistics and bioinformatic tools is the only way to dig out the meaningful information that is buried within tables comprising hundreds of rows and columns. This can be achieved with rigorous tools and procedures. However, there is always the risk of misinterpreting the message and losing relevant pieces of information.

In this framework, an appropriate use of TAC measurement both in food and in vivo can still provide support for the interpretation of complex phenomena and comprise a tool for sample screening when making a quick decision toward in-depth research investigations.

\section{REFERENCES}

1 Steinmetz KA and Potter JD, Vegetables, fruit, and cancer prevention: a review. J Am Diet Assoc 96:1027-1039 (1996).

2 Kohlmeier L, Simonsen N and Mottus K, Dietary modifiers of carcinogenesis. Environ Health Perspect 103:177-184 (1995).

3 Goodwin JS and Brodwick M, Diet, aging, and cancer. Clin Geriatr Med 11:577-589 (1995).

4 Rimm EB, Ascherio A, Giovannucci E, Spiegelman D, Stampfer MJ and Willett WC, Vegetable, fruit, and cereal fiber intake and risk of coronary heart disease among men. JAMA 275:447-451 (1996).

5 Gillman MW, Cupples LA, Gagnon D, Posner BM, Ellison RC, Castelli WP et al., Protective effect of fruits and vegetables on development of stroke in men. JAMA 273:1113-1117 (1995).

6 Pompella A, Sies H, Wacker R, Brouns F, Grune T, Biesalski HK et al., The use of total antioxidant capacity as surrogate marker for food 
quality and its effect on health is to be discouraged. Nutrition 30:791-793 (2014).

7 Fraga CG, Oteiza PI and Galleano M, In vitro measurements and interpretation of total antioxidant capacity. Biochim Biophys Acta 1840:931-934 (2014).

8 Rutkowski R, Pancewicz SA, Rutkowski K and Rutkowska J, Reactive oxygen and nitrogen species in inflammatory process. Pol Merkur Lekarski 23:131-136 (2007).

9 Ferreira ALA and Matsubara LS, Radicais livres: conceitos, doenças relacionadas, sistema de defesa e estresse oxidativo. Rev Ass Méd Bras 43:61-68 (1997).

10 Sánchez-Rodríguez C, Martín-Sanz E, Cuadrado E, Granizo JJ and Sanz-Fernández R, Protective effect of polyphenols on presbycusis via oxidative/nitrosative stress suppression in rats. Exp Gerontol 83:31-36 (2016)

11 Samet JM and Wages PA, Oxidative stress from environmental exposures. Curr Opin Toxicol 7:60-66 (2017).

12 Veloso ACA, Silva LM, Rodrigues N, Rebello LPG, Dias LG, Pereira JA et al., Perception of olive oils sensory defects using a potentiometric taste device. Talanta 176:610-618 (2018).

13 Moilanen J, Karonen M, Tähtinen P, Jacquet R, Quideau S and Salminen JP, Biological activity of ellagitannins: effects as anti-oxidants, pro-oxidants and metal chelators. Phytochemistry 125:65-72 (2016).

14 Prescha A, Grajzer M, Dedyk M and Grajeta H, The antioxidant activity and oxidative stability of cold-pressed oils. J Am Oil Chem Soc 91:1291-1301 (2014).

15 Zhang KQ, Bao Y, Wu P, Rosen RT and Ho CT, Antioxidative components of Tanshen (Salvia miltiorrhiza Bung). J Agric Food Chem 38:1194-1197 (1990).

16 Gordon $\mathrm{MH}$ and Kouukimska L, The effects of antioxidants on changes in oils during heating and deep-frying. J Sci Food Agric 68:347-353 (1995).

17 Carelli AA, Franco IC and Crapiste GH, Effectiveness of added natural antioxidants in sunflower oil. Grasas Aceites 56:303-310 (2005).

18 Mrabet A, García-Borrego A, Jiménez-Araujo A, Fernández-Bolaños A and Rodríguez-Gutiérrez $\mathrm{G}$, Phenolic extracts obtained from thermally treated secondary varieties of dates: antimicrobial and antioxidant properties. LWT - Food Sci Technol 79:416-422 (2017).

19 Comunian TA, Chaves IE, Thomazini M, Moraes ICF, Ferro-Furtado R, Castro IA et al., Development of functional yogurt containing free and encapsulated echium oil, phytosterol and sinapic acid. Food Chem 237:948-956 (2017).

20 Tańska M, Mikołajczak N and Konopka I, Comparison of the effect of sinapic and ferulic acids derivatives (4-vinylsyringol vs. 4-vinylguaiacol) as antioxidants of rapeseed, flaxseed, and extra virgin olive oils. Food Chem 240:679-685 (2018).

21 Macedo LFL, Rogero MM, Guimarães JP, Granato D, Lobato LP and Castro IA, Effect of red wines with different in vitro antioxidant activity on oxidative stress of high-fat diet rats. Food Chem 137:122-129 (2013).

22 Margraf T, Santos ENT, de Andrade EF, van Ruth SM and Granato D, Effects of geographical origin, variety and farming system on the chemical markers and in vitro antioxidant capacity of Brazilian purple grape juices. Food Res Int 82:145-155 (2016).

23 Ghani MA, Barril C, Bedgood DR and Prenzler PD, Measurement of antioxidant activity with the thiobarbituric acid reactive substances assay. Food Chem 230:195-207 (2017).

24 Makri S, Kafantaris I, Stagos D, Chamokeridou T, Petrotos K, Gerasopoulos K et al., Novel feed including bioactive compounds from winery wastes improved broilers' redox status in blood and tissues of vital organs. Food Chem Toxicol 102:24-31 (2017).

25 Gordon MH, Factors affecting lipid oxidation, in Understanding and Measuring the Shelf-Life of Food, ed. by Steele R. Woodhead Publishing, Cambridge, England. PP. 128-141 (2004).

26 Del Rio D, Stewart AJ and Pellegrini N, A review of recent studies on malondialdehyde as toxic molecule and biological marker of oxidative stress. Nutr Metab Cardiovasc Dis 15:316-328 (2005).

27 Yonny ME, Garcia EM, López A, Arrquy Jl and Nazareno MA, Measurement of malondialdehyde as oxidative stress biomarker in goat plasma by HPLC-DAD. Microchem J 129:281-285 (2016)

28 Amorati $\mathrm{R}$ and Valgimigli L, Advantages and limitations of common testing methods for antioxidants. Free Radic Res 49:633-649 (2015).
29 Pinchuk I, Shoval H, Dotan Y and Lichtenberg D, Evaluation of antioxidants: scope, limitations and relevance of assays. Chem Phys Lipids 165:638-647 (2012).

30 Huang $\mathrm{D}, \mathrm{Ou} \mathrm{B}$ and Prior RL, The chemistry behind antioxidant capacity assay. J Agric Food Chem 53:1841-1856 (2005).

31 Daker M, Abdullah N, Vikineswary S, Goh PC and Kuppusamy UR, Antioxidant from maize and maize fermented by Marasmiellus $\mathrm{sp}$. as stabiliser of lipid-rich foods. Food Chem 107:1092-1098 (2008).

32 Prieto MA, Vázquez JA and Murado MA, Crocin bleaching antioxidant assay revisited: application to microplate to analyse antioxidant and pro-oxidant activities. Food Chem 167:299-310 (2015).

33 Re R, Pellegrini N, Proteggente A, Pannala A, Yang M and Rice-Evans C, Antioxidant activity applying an improved ABTS radical cation decolourization assay. Free Radic Biol Med 26:1231-1237 (1999).

34 Brand-Williams W, Cuvelier ME and Berset C, Use of free-radical method to evaluate antioxidant activity. LWT-Food Sci Technol 28:25-30 (1995).

35 Benzie IF and Strain JJ, The ferric reducing ability of plasma (FRAP) as a measure of 'antioxidant power': the FRAP assay. Anal Biochem 239:70-76 (1996).

36 Singleton V, Orthofer R and Lamuela-Raventos RM, Analysis of total phenols and other oxidation substrates and antioxidants by means of Folin-Ciocalteau reagent. Methods Enzymol 299:152-178 (1999).

37 Berker Kl, Ozdemir OFA, Ozyurt D, Demirata B and Apak R, Modified Folin-Ciocalteu antioxidant capacity assay for measuring lipophilic antioxidants. J Agric Food Chem 61:4783-4791 (2013).

38 Apak R, Guclu K, Ozyurek M and Celik SE, Mechanism of antioxidant capacity assays and the CUPRAC (cupric ion reducing antioxidant capacity) assay. Microchim Acta 160:413-419 (2008).

39 Gokmen V, Serpen A and Fogliano V, Direct measurement of the total antioxidant capacity of foods: the 'QUENCHER' approach. Trends Food Sci Technol 20:278-288 (2009).

40 Apak R, Özyürek M, Güçlü K and Çapanoğlu E, Antioxidant activity/capacity measurement. 1. classification, physicochemical principles, mechanisms, and electron transfer (ET)-based assays. J Agric Food Chem 64:997-1027 (2016).

41 Lettieri-Barbato D, Tomei F, Sancini A, Morabito G and Serafini M, Effect of plant foods and beverages on plasma non-enzymatic antioxidant capacity in human subjects: a meta-analysis. Br J Nutr 109:1544-1556 (2013).

42 Błauż A, Pilaszek T, Grzelak A, Dragan A and Bartosz G, Interaction between antioxidants in assays of total antioxidant capacity. Food Chem Toxicol 46:2365-2368 (2008).

43 Harnly J, Antioxidant methods. J Food Compost Anal 64:145-146 (2017).

44 Niki E, Assessment of antioxidant capacity in vitro and in vivo. Free Radic Biol Med 49:503-515 (2010).

45 Santos JS, Deolindo CTP, Esmerino LA, Genovese MI, Fujita A, Marques $\mathrm{MB}$ et al., Effects of time and extraction temperature on phenolic composition and functional properties of red rooibos (Aspalathus linearis). Food Res Int 89:476-487 (2016).

46 Cömert ED and Gökmen V, Evolution of food antioxidants as a core topic of food science for a century. Food Res Int 105:76-93 (2018).

47 López-Alarcón C and Denicol A, Evaluating the antioxidant capacity of natural products. A review on chemical and cellular-based assays. Anal Chim Acta 763:1 - 10 (2013).

48 Wan H, Liu D, Yu X, Sun H and Li Y, A Caco-2 cell-based quantitative antioxidant activity assay for antioxidants. Food Chem 175:601-608 (2015)

49 Schaich KM, Tian $X$ and Xie J, Hurdles and pitfalls in measuring antioxidant efficacy: a critical evaluation of ABTS, DPPH, and ORAC assays. J Funct Foods 14:111-125 (2015).

50 Meng D, Zhang $\mathrm{P}$, Zhang L, Wang $\mathrm{H}$, Ho CT, Li S et al., Detection of cellular redox reactions and antioxidant activity assays. J Funct Foods 37:467-479 (2017).

51 Kellett ME, Greenspan P and Pegg RB, Modification of the cellular antioxidant activity (CAA) assay to study phenolic antioxidants in a Caco-2 cell line. Food Chem 244:359-363 (2018).

52 Granato D, Shahidi F, Wrolstad R, Kilmartin P, Melton LD, Hidalgo FJ et al., Antioxidant activity, total phenolics and flavonoids contents: should we ban in vitro screening methods? Food Chem 264:471-475 (2018).

53 Serafini M, Ghiselli A and Ferro-Luzzi A, Red wine, tea, and antioxidants. Lancet 344:626 (1994). 
54 Maxwell S, Cruickshank A and Thorpe G, Red wine and antioxidant activity in serum. Lancet 344:193-194 (1994).

55 Yen GC and Chen HY, Antioxidant activity of various tea extracts in relation to their antimutagenicity. J Agric Food Chem 43:27-32 (1995).

56 Weisburger $\mathrm{JH}$, Mechanisms of action of antioxidants as exemplified in vegetables, tomatoes and tea. Food Chem Toxicol 9-10:943-948 (1999).

57 Ivanov V, Carr AC and Frei B, Red wine antioxidants bind to human lipoproteins and protect them from metal ion-dependent and -independent oxidation. J Agric Food Chem 49:4442-4449 (2001).

58 Castro IA, Rogero MM, Junqueira RM and Carrapeiro MM, Free radical scavenger and antioxidant capacity correlation of $\alpha$-tocopherol and Trolox measured by three in vitro methodologies. Int J Food Sci Nutr 57:75-82 (2006).

59 Alonso AM, Guillén DA, Barroso CG, Puertas B and García A, Determination of antioxidant activity of wine byproducts and its correlation with polyphenolic content. J Agric Food Chem 50:5832-5836 (2002).

60 Llorach R, Espín JC, Tomás-Barberán FA and Ferreres F, Valorization of cauliflower (Brassica oleracea L. var. botrytis) by-products as a source of antioxidant phenolics. J Agric Food Chem 51:2181-2187 (2003).

61 Louli V, Ragoussis N and Magoulas K, Recovery of phenolic antioxidants from wine industry by-products. Bioresour Technol 92:201-208 (2004).

62 Karnopp A, Oliveira KG, Andrade EF, Postingher BM and Granato D, Optimization of an organic yogurt based on sensorial, nutritional, and functional perspectives. Food Chem 233:401-411 (2017).

63 Lucera A, Costa C, Marinelli V, Saccotelli MA, Del Nobile MA and Conte A, Fruit and vegetable by-products to fortify spreadable cheese. Antioxidants 7:61 (2018).

64 Šporin M, Avbelj M, Kovač B and Možina SS, Quality characteristics of wheat flour dough and bread containing grape pomace flour. Food Sci Technol Int 24:251-263 (2018).

65 Colantuono A, Ferracane R and Vitaglione P, In vitro bioaccessibility and functional properties of polyphenols from pomegranate peels and pomegranate peels-enriched cookies. Food Funct 7:4247-4258 (2016).

66 Colantuono A, Vitaglione $\mathrm{P}$, Ferracane $\mathrm{R}$, Campanella $\mathrm{OH}$ and Hamaker BR, Development and functional characterization of new antioxidant dietary fibers from pomegranate, olive and artichoke by-products. Food Res Int 101:155-164 (2017).

67 Colantuono A, Ferracane R and Vitaglione P, Potential bioaccessibility and functionality of polyphenols and cynaropicrin from breads enriched with artichoke stem. Food Chem 245:838-844 (2018).

68 Halvorsen BL, Holte K, Myhrstad MC, Barikmo I, Hvattum E, Remberg SF et al., A systematic screening of total antioxidants in dietary plants. J Nutr 132:461-471 (2002).

69 Halvorsen BL, Carlsen MH, Phillips KM, Bøhn SK, Holte K, Jacobs DR Jr et al., Content of redox-active compounds (ie, antioxidants) in foods consumed in the United States. Am J Clin Nutr 84:95-135 (2006).

70 Carlsen MH, Halvorsen BL, Holte K, Bøhn SK, Dragland S, Sampson L et al., The total antioxidant content of more than 3100 foods, beverages, spices, herbs and supplements used worldwide. Nutr $J$ 9:3 (2010) doi:http://www.nutritionj.com/content/9/1/3.

71 Halvorsen $\mathrm{BL}$ and Blomhoff $\mathrm{R}$, Validation of a quantitative assay for the total content of lipophilic and hydrophilic antioxidants in foods. Food Chem 127:761-768 (2011).

72 Wu X, Beecher GR, Holden JM, Haytowitz DB, Gebhardt SE and Prior $\mathrm{RL}$, Lipophilic and hydrophilic antioxidant capacities of common foods in the United States. J Agric Food Chem 52:4026-4037 (2004).

73 Pellegrini N, Del Rio D, Colombi B, Bianchi M and Brighenti F, Total antioxidant capacity of plants foods, beverages and oil consumed in Italy assessed by three different in vitro assays. J Agric Food Chem 51:260-264 (2003).

74 Pellegrini N, Serafini M, Salvatore S, Del Rio D, Bianchi M and Brighenti F, Total antioxidant capacity of spices, dried fruits, nuts, pulses, cereals and sweets consumed in Italy assessed by three different in vitro assays. Mol Nutr Food Res 50:1030-1038 (2006).

75 Pellegrini N, Visioli F, Buratti S and Brighenti F, Direct analysis of total antioxidant activity of olive oil and studies on the influence of heating. J Agric Food Chem 49:2532-2538 (2001).

76 Sosulski F, Krygier $\mathrm{K}$ and Hogge L, Free, esterified, and insoluble-bound phenolic acids. 3. Composition of phenolic acids in cereal and potato flours. J Agric Food Chem 30:337-340 (1982).

77 Pellegrini N, Miglio C, Del Rio D, Salvatore S, Serafini M and Brighenti F, Effect of domestic cooking methods on total antioxidant capacity of vegetables. Int J Food Sci Nutr 60:12-22 (2009).

78 Vijaya Kumar Reddy C, Sreeramulu D and Raghunath M, Antioxidant activity of fresh and dry fruits commonly consumed in India. Food Res Int 43:285-288 (2010).

79 Sreeramulu D and Raghunath M, Antioxidant activity and phenolic content of roots, tubers and vegetables commonly consumed in India. Food Res Int 43:1017-1020 (2010).

80 Isabelle M, Lee BL, Lim MT, Koh W-P, Huang D and Ong CN, Antioxidant activity and profiles of common fruits in Singapore. Food Chem 123:77-84 (2010).

81 Isabelle M, Lee BL, Lim MT, Koh W-P, Huang D and Ong CN, Antioxidant activity and profiles of common vegetables in Singapore. Food Chem 120:993-1003 (2010).

82 Takebayashi J, Oki T, Watanabe J, Yamasaki K, Chen J, Sato-Furukawa M et al., Hydrophilic antioxidant capacities of vegetables and fruits commonly consumed in Japan and estimated average daily intake of hydrophilic antioxidants from these foods. J Food Comp Anal 29:25-31 (2013).

83 Rautenbach F and Venter I, Hydrophilic and lipophilic antioxidant capacity of commonly consumed South African fruits, vegetables, grains, legumes, fats/oils and beverages. J Food Comp Anal 23:753-761 (2010).

84 Pellegrini N, Salvatore S, Valtueña S, Bedogni G, Porrini M, Pala V et al., Development and validation of a food frequency questionnaire for the assessment of dietary total antioxidant capacity. J Nutr 137:93-98 (2007).

85 Rautiainen $S$, Serafini $M$, Morgenstern $R$, Prior $R L$ and Wolk A, The validity and reproducibility of food-frequency questionnaire-based total antioxidant capacity estimates in Swedish women. Am J Clin Nutr 87:1247-1253 (2008).

86 Yang M, Wang Y, Davis CG, Lee SG, Fernandez ML, Koo Sl et al., Validation of an FFQ to assess short-term antioxidant intake against $30 \mathrm{~d}$ food records and plasma biomarkers. Public Health Nutr 17:297-306 (2014).

87 Floegel A, Kim DO, Chung SJ, Song WO, Fernandez ML, Bruno RS et al., Development and validation of an algorithm to establish a total antioxidant capacity database of the US diet. Int J Food Sci Nutr 61:600-623 (2010).

88 Yang M, Wang Y, Davis CG, Lee SG, Fernandez ML, Koo SI et al., Validation of an FFQ to assess antioxidant intake in overweight postmenopausal women. Public Health Nutr 17:1467-1475 (2014).

89 Serafini M, Bellocco R, Wolk A and Ekström AM, Total antioxidant potential of fruit and vegetables and risk of gastric cancer. Gastroenterology 123:985-991 (2002).

90 Agudo A, Cabrera L, Amiano P, Ardanaz E, Barricarte A, Berenguer T et al., Fruit and vegetable intakes, dietary antioxidant nutrients, and total mortality in Spanish adults: findings from the Spanish cohort of the European Prospective Investigation into Cancer and Nutrition (EPIC-Spain). Am J Clin Nutr 85:1634-1642 (2007).

91 Henríquez-Sánchez P, Sánchez-Villegas A, Ruano-Rodríguez C, Gea A, Lamuela-Raventós RM, Estruch R et al., Dietary total antioxidant capacity and mortality in the PREDIMED study. Eur J Nutr 55:227-236 (2016).

92 Bastide N, Dartois L, Dyevre V, Dossus L, Fagherazzi G, Serafini M et al., Dietary antioxidant capacity and all-cause and cause-specific mortality in the E3N/EPIC cohort study. Eur J Nutr 56:1233-1243 (2017).

93 Rautiainen S, Levitan EB, Orsini N, Åkesson A, Morgenstern R, Mittleman MA et al., Total antioxidant capacity from diet and risk of myocardial infarction: a prospective cohort of women. Am J Med 125:974-980 (2012).

94 Rautiainen S, Levitan EB, Mittleman MA and Wolk A, Total antioxidant capacity of diet and risk of heart failure: a population-based prospective cohort of women. Am J Med 126:494-500 (2013).

95 Rautiainen S, Larsson S, Virtamo J and Wolk A, Total antioxidant capacity of diet and risk of stroke: a population-based prospective cohort of women. Stroke 43:335-340 (2012).

96 Del Rio D, Agnoli C, Pellegrini N, Krogh V, Brighenti F, Mazzeo T et al., Total antioxidant capacity of the diet is associated with lower risk of ischemic stroke in a large Italian cohort. J Nutr 141:118-123(2011).

97 Colarusso L, Serafini M, Lagerros YT, Nyren O, La Vecchia C, Rossi $\mathrm{M}$ et al., Dietary antioxidant capacity and risk for stroke 
in a prospective cohort study of Swedish men and women. Nutrition 33:234-239 (2017).

98 Devore EE, Feskens E, Ikram MA, den Heijer T, Vernooij M, van der Lijn $\mathrm{F}$ et al., Total antioxidant capacity of the diet and major neurologic outcomes in older adults. Neurology 80:904-910 (2013).

99 Devore EE, Kang JH, Stampfer MJ and Grodstein F, Total antioxidant capacity of diet in relation to cognitive function and decline. Am J Clin Nutr 92:1157-1164 (2010).

100 Mekary RA, Wu K, Giovannucci E, Sampson L, Fuchs C, Spiegelman D et al., Total antioxidant capacity intake and colorectal cancer risk in the Health Professionals Follow-up Study. Cancer Causes Control 21:1315-1321 (2010).

101 Vece MM, Agnoli C, Grioni S, Sieri S, Pala V, Pellegrini N et al., Dietary total antioxidant capacity and colorectal cancer in the Italian EPIC cohort. PLOS ONE 10:e0142995 (2015).

102 La Vecchia C, Decarli A, Serafini M, Parpinel M, Bellocco R, Galeone C et al., Dietary total antioxidant capacity and colorectal cancer: a large case-control study in Italy. Int J Cancer 133:1447-1451 (2013).

103 Vance TM, Wang Y, Su LJ, Fontham ET, Steck SE, Arab L et al., Dietary total antioxidant capacity is inversely associated with prostate cancer aggressiveness in a population-based study. Nutr Cancer 68:214-224 (2016).

104 Zamora-Ros R, Fedirko V, Trichopoulou A, González CA, Bamia C, Trepo E et al., Dietary flavonoid, lignan and antioxidant capacity and risk of hepatocellular carcinoma in the European prospective investigation into cancer and nutrition study. Int J Cancer 133:2429-2443 (2013).

105 Lucas AL, Bosetti C, Boffetta P, Negri E, Tavani A, Serafini M et al., Dietary total antioxidant capacity and pancreatic cancer risk: an Italian case-control study. Br J Cancer 115:102-107 (2016).

106 Pantavos A, Ruiter R, Feskens EF, de Keyser CE, Hofman A, Stricker $\mathrm{BH}$ et al., Total dietary antioxidant capacity, individual antioxidant intake and breast cancer risk: the Rotterdam Study. Int J Cancer 136:2178-2186 (2015).

107 Gifkins D, Olson SH, Demissie K, Lu SE, Kong AN and Bandera EV, Total and individual antioxidant intake and endometrial cancer risk: results from a population-based case-control study in New Jersey. Cancer Causes Control 23:887-895 (2012).

108 Gifkins D, Olson SH, Paddock L, King M, Demissie K, Lu SE et al., Total and individual antioxidant intake and risk of epithelial ovarian cancer. BMC Cancer 12:211 (2012).

109 Rossi M, Tavani A, Ciociola V, Ferraroni M, Parpinel M, Serafini M et al., Dietary total antioxidant capacity in relation to endometrial cancer risk: a case-control study in Italy. Cancer Causes Control 27:425-431 (2016).

110 Mancini FR, Affret A, Dow C, Balkau B, Bonnet F, Boutron-Ruault MC et al., Dietary antioxidant capacity and risk of type 2 diabetes in the large prospective E3N-EPIC cohort. Diabetologia 61:308-316 (2018).

111 Okubo H, Syddall HE, Phillips DI, Sayer AA, Dennison EM, Cooper C et al., Dietary total antioxidant capacity is related to glucose tolerance in older people: the Hertfordshire cohort study. Nutr Metab Cardiovasc Dis 24:301 - 308 (2014).

112 Psaltopoulou T, Panagiotakos DB, Pitsavos C, Chrysochoou C, Detopoulou P, Skoumas J et al., Dietary antioxidant capacity is inversely associated with diabetes biomarkers: the ATTICA study. Nutr Metab Cardiovasc Dis 21:561 -567 (2011).

113 Bahadoran Z, Golzarand M, Mirmiran P, Shiva N and Azizi F, Dietary total antioxidant capacity and the occurrence of metabolic syndrome and its components after a 3-year follow-up in adults: Tehran lipid and glucose study. Nutr Metab 9:70 (2012).

114 Hermsdorff HH, Puchau B, Volp AC, Barbosa KB, Bressan J, Zulet MÁ et al., Dietary total antioxidant capacity is inversely related to central adiposity as well as to metabolic and oxidative stress markers in healthy young adults. Nutr Metab 8:59 (2011).

115 Puchau B, Zulet MA, de Echávarri AG, Hermsdorff $\mathrm{HH}$ and Martínez JA, Dietary total antioxidant capacity is negatively associated with some metabolic syndrome features in healthy young adults. Nutrition 26:534-541 (2010).

116 Kim K, Vance TM and Chun OK, Greater total antioxidant capacity from diet and supplements is associated with a less atherogenic blood profile in U.S. adults. Nutrients 8:15 (2016).

117 Brighenti F, Valtueña S, Pellegrini N, Ardigò D, Del Rio D, Salvatore $\mathrm{S}$ et al., Total antioxidant capacity of the diet is inversely and independently related to plasma concentration of high-sensitivity
C-reactive protein in adult Italian subjects. Br J Nutr 93:619-625 (2005).

118 Wang Y, Yang M, Lee SG, Davis CG, Koo SI, Fernandez ML et al., Diets high in total antioxidant capacity improve risk biomarkers of cardiovascular disease: a 9-month observational study among overweight/obese postmenopausal women. Eur J Nutr 53:1363-1369 (2014).

119 Kobayashi S, Murakami K, Sasaki S, Uenishi K, Yamasaki M, Hayabuchi $\mathrm{H}$ etal., Dietary total antioxidant capacity from different assays in relation to serum C-reactive protein among young Japanese women. Nutr J 11:91 (2012).

120 Detopoulou P, Panagiotakos DB, Chrysohoou C, Fragopoulou E, Nomikos T, Antonopoulou S et al., Dietary antioxidant capacity and concentration of adiponectin in apparently healthy adults: the ATTICA study. Eur J Clin Nutr 64:161 - 168 (2010).

121 Svilaas A, Sakhi AK, Andersen LF, Svilaas T, Ström EC, Jacobs DR Jr et al., Intakes of antioxidants in coffee, wine, and vegetables are correlated with plasma carotenoids in humans. J Nutr 134:562-567 (2004).

122 Valtueña S, Del Rio D, Pellegrini N, Ardigò D, Franzini L, Salvatore S et al., The total antioxidant capacity of the diet is an independent predictor of plasma beta-carotene. Eur J Clin Nutr 61:69-76 (2007).

123 Puchau B, Zulet MA, de Echávarri AG, Hermsdorff HH and Martínez JA, Dietary total antioxidant capacity: a novel indicator of diet quality in healthy young adults. J Am Coll Nutr 28:648-656 (2009).

124 Perry G, Cash AD and Smith MA, Alzheimer disease and oxidative stress. J Biomed Biotechnol 2:120-123 (2002).

125 Gautam N, Das S, Mahapatra SK, Chakraborty SP, Kundu PK and Roy S, Age associated oxidative damage in lymphocytes. Oxid Med Cell Longev 3:275-282 (2010).

126 Hwang O, Role of oxidative stress in Parkinson's disease. Exp Neurobiol 22:11-17 (2013)

127 Parry TL, Melehani JH, Ranek MJ and Willis MS, Functional amyloid signaling via the inflammasome, necrosome, and signalosome: new therapeutic targets in heart failure. Front Cardiovasc Med 2:25 (2015).

128 Huang WJ, Zhang $X$ and Chen WW, Role of oxidative stress in Alzheimer's disease. Biomed Rep 4:519-522 (2016).

129 Poulose N and Raju R, Aging and injury: alterations in cellular energetics and organ function. Aging Dis 5:101-108 (2014).

130 Marrocco I, Altieri F and Peluso I, Measurement and clinical significance of biomarkers of oxidative stress in humans. Oxid Med Cell Longev 2017:6501046 (2017).

131 Serafini M, Ghiselli A and Ferro-Luzzi A, In vivo antioxidant effect of green and black tea in man. Eur J Clin Nutr 50:28-23 (1996).

132 Maxwell S and Thorpe G, Tea flavonoids have little short term impact on serum antioxidant activity. BMJ 313:229 (1996).

133 Cao G, Booth SL, Sadowski JA and Prior RL, Increases in human plasma antioxidant capacity after consumption of controlled diets high in fruit and vegetables. Am J Clin Nutr 68:1081-1087 (1998).

134 Cao G, Russell RM, Lischner N and Prior RL, Serum antioxidant capacity is increased by consumption of strawberries, spinach, red wine or vitamin C in elderly women. J Nutr 128:2383-2390 (1998).

135 Miller ER, Appel LJ and Risby TH, Effect of dietary patterns on measures of lipid peroxidation: results from a randomized clinical trial. Circulation 98:2390-2395 (1998).

136 Castenmiller JJM, Lauridsen ST, Dragsted LO, van het Hof KH, Linssen JPH and West $\mathrm{CE}, \beta$-Carotene does not change markers of enzymatic and nonenzymatic antioxidant activity in human blood. J Nutr 129:2162-2169 (1999).

137 Bub A, Watzl B, Abrahamse L, Delincée H, Adam S, Wever J et al., Moderate intervention with carotenoid-rich vegetable products reduces lipid peroxidation in men. J Nutr 130:2200-2206 (2000).

138 Pellegrini N, Riso $\mathrm{P}$ and Porrini $\mathrm{M}$, Tomato consumption does not affect the total antioxidant capacity of plasma. Nutrition 16:268-271 (2000)

139 Young JF, Nielsen SE, Haraldsdottir J, Daneshvar B, Lauridsen ST, Knuthsen $\mathrm{P}$ et al., Effect of fruit juice intake on urinary quercetin excretion and biomarkers of antioxidative status. Am J Clin Nutr 69:87-94 (1999).

140 Record IR, Dreosti IE and McInerney JK, Changes in plasma antioxidant status following consumption of diets high or low in fruit and vegetables or following dietary supplementation with an antioxidant mixture. Br J Nutr 85:459-464 (2001). 
141 McKay DL, Perrone G, Rasmussen H, Dallal G, Hartman W, Cao G et al., The effects of a multivitamin/mineral supplement on micronutrient status, antioxidant capacity and cytokine production in healthy older adults consuming a fortified diet. J Am Coll Nutr 19:613-621 (2000).

142 Serafini $M$ and Del Rio $D$, Understanding the association between dietary antioxidants, redox status and disease: is the total antioxidant capacity the right tool? Redox Rep 9:145-152 (2004).

143 Lotito SB and Frei B, Consumption of flavonoid-rich foods and increased plasma antioxidant capacity in humans: cause, consequence, or epiphenomenon? Free Radic Biol Med 41:1727-1746 (2006).

144 lalongo C, Preanalytic of total antioxidant capacity assays performed in serum, plasma, urine and saliva. Clin Biochem 50:356-363 (2017).

145 Wang XL, Rainwater DL, VandeBerg JF, Mitchell BD and Mahaney MC, Genetic contributions to plasma total antioxidant activity. Arterioscler Thromb Vasc Biol 21:1190-1195 (2001).

146 Young-Sam K, Regulation of Nrf2-mediated phase II detoxification and anti-oxidant genes. Biomol Ther (Seoul) 20:144-151 (2012).

147 Yu M, Xu M, Liu Y, Yang W, Rong Y, Yao P et al., Nrf2/ARE is the potential pathway to protect Sprague-Dawley rats against oxidative stress induced by quinocetone. Regul Toxicol Pharmacol 66:279-285 (2013).

148 Stefanson AL and Bakovic M, Dietary regulation of Keap1/Nrf2/ARE pathway: focus on plant-derived compounds and trace minerals. Nutrients 6:3777-3801 (2014).

149 Serafini M, Miglio C, Peluso I and Petrosino T, Modulation of plasma non enzymatic antioxidant capacity (NEAC) by plant foods: the role of polyphenols. Curr Top Med Chem 11:1821 - 1846 (2011).

150 Clemente JC, Ursell LK, Parfrey LW and Knight R, The impact of gut microbiota on human health: an integrative view. Cell 148:1258-1270 (2012).
151 Shanahan F, van Sinderen D, O'Toole PW and Stanton C, Feeding the microbiota: transducer of nutrient signals for the host. Gut 66:1709-1717 (2017).

152 De Filippis F, Vitaglione P, Cuomo R, Berni Canani R and Ercolini D, Dietary interventions to modulate the gut microbiome - how far away are we from precision medicine. Inflamm Bowel Dis 24:2142-2154 (2018)

153 Badehnoosh B, Karamali M, Zarrati M, Jamilian M, Bahmani F, Tajabadi-Ebrahimi $M$ et al., The effects of probiotic supplementation on biomarkers of inflammation, oxidative stress and pregnancy outcomes in gestational diabetes. J Matern Fetal Neonatal Med 31:1128-1136 (2018).

154 Nabhani Z, Hezaveh SJG, Razmpoosh E, Asghari-Jafarabadi M and Gargari BP, The effects of synbiotic supplementation on insulin resistance/sensitivity, lipid profile and total antioxidant capacity in women with gestational diabetes mellitus: a randomized double blind placebo controlled clinical trial. Diabetes Res Clin Pract 138:149-157 (2018).

155 Soleimani A, Zarrati Mojarrad M, Bahmani F, Taghizadeh M, Ramezani M, Tajabadi-Ebrahimi M et al., Probiotic supplementation in diabetic hemodialysis patients has beneficial metabolic effects. Kidney Int 91:435-442 (2017).

156 Açar ÖÇ, Gökmen V, Pellegrini N and Fogliano V, Direct evaluation of the total antioxidant capacity of raw and roasted pulses, nuts and seeds. Eur Food Res Technol 229:961-969 (2009).

157 Charalampos P, Khaled R, Roidaki A and Sinanoglou V, Antioxidant capacity and antimicrobial activity of selected aromatic Egyptian plants promising raw materials for 'superfoods' and dietary supplements. Agro Food Ind Hi Tech 27:35-38 (2016).

158 Foti MC and Amorati R, Non-phenolic radical-trapping antioxidants. J Pharm Pharmacol 61:1435-1448 (2009).

159 Alpha-Tocopherol, Beta Carotene Cancer Prevention Study Group, The effect of vitamin $\mathrm{E}$ and beta carotene on the incidence of lung cancer and other cancers in male smokers. $N$ Engl J Med 330:1029-1035 (1994). 